\title{
$\alpha 2$-Chimaerin Is Required for Eph Receptor-Class-Specific Spinal Motor Axon Guidance and Coordinate Activation of Antagonistic Muscles
}

\author{
Tzu-Jen Kao, ${ }^{3,5,6 *}$ Georgina C.B. Nicholl, ${ }^{1 \star}$ Jamie A. Johansen, ${ }^{7}$ Artur Kania, ${ }^{3,4}$ and Asim A. Beg ${ }^{1,2}$ \\ ${ }^{1}$ Department of Pharmacology, University of Michigan Medical School, Ann Arbor, Michigan 48109, ${ }^{2}$ Neuroscience Program, University of Michigan, Ann \\ Arbor MI 48109, ${ }^{3}$ Institut de Recherches Cliniques de Montréal, Montréal, QC H2W 1R7 Canada, ${ }^{4}$ Departments of Anatomy and Cell Biology and Biology, \\ Division of Experimental Medicine, McGill University Montréal, Quebec H3A 2B2, Canada, and Faculté de Médecine, Université de Montréal, Montréal, \\ Quebec H3C 3J7, Canada, ${ }^{5}$ Graduate Institute of Neural Regenerative Medicine, College of Medical Science and Technology and ${ }^{6}$ Center for Neurotrauma \\ and Neuroregeneration, Taipei Medical University, Taipei, Taiwan, and ${ }^{7}$ College of Medicine, Central Michigan University, Mount Pleasant, Michigan 48859
}

Axonal guidance involves extrinsic molecular cues that bind growth cone receptors and signal to the cytoskeleton through divergent pathways. Some signaling intermediates are deployed downstream of molecularly distinct axon guidance receptor families, but the scope of this overlap is unclear, as is the impact of embryonic axon guidance fidelity on adult nervous system function. Here, we demonstrate that the Rho-GTPase-activating protein $\alpha 2$-chimaerin is specifically required for EphA and not EphB receptor signaling in mouse and chick spinal motor axons. Reflecting this specificity, the loss of $\alpha 2$-chimaerin function disrupts the limb trajectory of extensor-muscleinnervating motor axons the guidance of which depends on EphA signaling. These embryonic defects affect coordinated contraction of antagonistic flexor-extensor muscles in the adult, indicating that accurate embryonic motor axon guidance is critical for optimal neuromuscular function. Together, our observations provide the first functional evidence of an Eph receptor-class-specific intracellular signaling protein that is required for appropriate neuromuscular connectivity.

Key words: axon guidance; chimaerin; motor neurons; muscle contraction

\section{Introduction}

Axon guidance ligands form structurally related families, raising the question of whether their homologous receptors share molecular strategies that relay extracellular signals to the cytoskeleton. Disruption of ligand-receptor interactions causes embryonic axon trajectory errors; however, their link to specific adult neuronal circuit function defects is unclear (Tessier-Lavigne and Goodman, 1996; Bashaw and Klein, 2010; Kolodkin and Tessier-Lavigne, 2011).

Ephrins and their Eph tyrosine kinase receptors have been implicated in many axon guidance processes (Klein, 2012). Ephs

Received Oct. 7, 2014; revised Dec. 2, 2014; accepted Dec. 14, 2014.

Author contributions: T.-J.K., G.C.B.N., J.A.J., A.K., and A.A.B. designed research;T.-J.K., G.C.B.N., J.A.J., A.K., and A.A.B. performed research; A.K. and A.A.B. contributed unpublished reagents/analytic tools; T.-J.K., G.C.B.N., J.A.J., A.K., and A.A.B. analyzed data; T.-J.K., G.C.B.N., J.A.J., A.K., and A.A.B. wrote the paper.

This work was supported by The Hartwell Foundation, March of Dimes, Alfred P. Sloan Foundation (to A.A.B.), National Science Council, Taipei Medical University (Grants NSC102-2320-B-038-056-MY2 and TMU102-AE1-B22 to to T.-J.K.), Canadian Institutes of Health Research, Canada Foundation for Innovation, Brain Canada, and the W. Garfield Weston Foundation (to A.K.). We thank members of the Beg and Kania laboratory for comments on the manuscript, Meirong Liang and Chris Valdez for technical assistance, and William Dauer for generously sharing equipment and technical expertise in locomotor analysis.

The authors declare no competing financial interests.

*T.-J.K. and G.C.B.N. contributed equally to this work.

Correspondence should be addressed to either of the following: Asim A. Beg, Department of Pharmacology, 1301D MSRB III, University of Michigan Medical School, 1150 W. Medical Center Dr., Ann Arbor, MI 48109, E-mail: asimbeg@umich.edu; or Artur Kania, Institut de Recherches Cliniques de Montréal, Montréal, QC H2W 1R7 Canada. E-mail: artur.kania@ircm.qc.ca.

DOI:10.1523/JNEUROSCI.4151-14.2015

Copyright $\odot 2015$ the authors $\quad 0270-6474 / 15 / 352344-14 \$ 15.00 / 0$ bind mostly same-class ligands and elicit growth cone collapse, suggesting that they might share common intracellular signaling effectors. In some cellular contexts, different EphA receptors elicit different responses to the same ligand (Seiradake et al., 2013), suggesting that some intracellular effectors are receptor specific. Eph signals converge onto the Rho family of GTPases (RhoA, Rac1, Cdc42), which control growth cone cytoskeletal dynamics. This relay is performed by Rho-GTPase-activating proteins (GAPs) and guanine nucleotide exchange factors (GEFs), which inactivate or activate Rho-GTPases, respectively (Wong et al., 2001; Luo, 2002; Ng et al., 2002; Govek et al., 2005; Bashaw and Klein, 2010). Structural diversity of GAPs and GEFs enables them to interact preferentially with selected axon guidance receptors, whereas their conserved domains enable coupling to a limited set of Rho GTPases. For example, ephexin1 and Vav2 are GEFs specific for EphA and EphB receptors required for RhoA and Racl activation, respectively (Shamah et al., 2001; Cowan et al., 2005). $\alpha 2$-chimaerin is a Rac1-inactivating GAP, binding Ephs from both A and B classes (Beg et al., 2007; Iwasato et al., 2007; Shi et al., 2007; Wegmeyer et al., 2007), suggesting that it might be a universal effector of Eph signaling. Importantly, gain-of-function mutations in the human gene encoding $\alpha 2$-chimaerin cause Duane's retraction syndrome (DRS; Miyake et al., 2008), a congenital oculomotor defect.

Limb muscle innervation by spinal lateral motor column (LMC) motor neurons is a binary axon guidance paradigm: lateral LMC and medial LMC axons, upon arrival in the limb, in- 
nervate dorsal or ventral limb muscles, respectively (Landmesser, 1978; Lance-Jones and Landmesser, 1981; Luria and Laufer, 2007). Ephrin:Eph signaling plays a critical role in this selection: EphA-expressing lateral LMC axons select the dorsal limb nerve in response to ventral limb ephrin-As (Helmbacher et al., 2000; Eberhart et al., 2002; Kania and Jessell, 2003; Kao et al., 2012). Similarly, EphB signaling in response to dorsal limb ephrin-Bs guides medial LMC axons into the ventral limb nerve (Luria et al., 2008). This paradigm can be used to identify the functionally relevant intracellular effectors of Eph signaling (Kao et al., 2009).

Here, we demonstrate that $\alpha 2$-chimaerin is required for LMC axon guidance and its loss and gain-of-function block EphA signaling, but not EphB-dependent signaling. Furthermore, LMC misprojections in $\alpha 2$-chimaerin mouse mutants persist in adults and lead to specific hindlimb neuromuscular function defects. Together, these findings represent a step toward decoding the intracellular logic of Rho-GTPase function in axon guidance and its relevance for adult nervous system function.

\section{Materials and Methods}

\section{Molecular biology}

The characterization of expression constructs, including $e[$ Isl1]::GFP, EphB2::GFP, EphA4::GFP, $\alpha 2$-chimaerin ( $\alpha 2$-chi), $\alpha 2$-chi::GFP, $\alpha 2-c^{2} i^{N 94 H}:: G F P$, and $\alpha 2-c h i^{4 Y R V}:: G F P$ has been described previously (Hall et al., 2001; Kania and Jessell, 2003; Beg et al., 2007; Kao et al., 2009; Palmesino et al., 2010).

In situ hybridization cRNA probes were obtained as follows (Kao et al., 2009): target sequences amplification primers were designed using Primer3 version 0.4.0 software (Rozen and Skaletsky, 2000) and the probe size was set at 600 to $800 \mathrm{bp}$. One-step RT-PCR was performed (Qiagen) using the designed primers containing T7 polymerase promoters (Invitrogen) to make and amplify cDNA template from chick HH st. 25/26 or mouse embryonic day 11.5 (e11.5) pooled brain RNA. The PCR product was purified by gel electrophoresis in $1 \%$ agarose gel and gel extraction using QIAquick gel extraction kit (Qiagen). The purified DNA was then reamplified by PCR. The yield of DNA was estimated by the Low DNA Mass Ladder (Invitrogen) after gel electrophoresis. DIG-labeled RNA probes were synthesized by in vitro transcription with T7 RNA polymerase using DIG RNA labeling kit (Roche). All probes were verified by sequencing. The source of sequence and the recognized region for each probe are described as follows: chick $\alpha$-chimaerin (NM_001012952, 9301679), mouse $\alpha 2$-chimaerin (NM_029716, 275-992). The details of Isl1 and Lim1 probes have been described previously (Tsuchida et al., 1994a).

\section{Chick in ovo electroporation}

Chick spinal cord electroporation of expression plasmids was performed at HH st. 18/19, generally as described previously (Momose et al., 1999; Luria et al., 2008). In brief, a 5-10 $\mu \mathrm{g} / \mu \mathrm{l}$ solution of plasmid DNA in TE buffer, pH 7.5 (10 mM Tris-HCl, Fisher Scientific, and 1 mM EDTA; Invitrogen) was injected into the lumbar neural tube through a small eggshell window under a Discovery V12 stereomicroscope (Zeiss). Lower bodies of chick embryos were then electroporated with platinum/iridium electrodes (FHC) and the TSS20 electroporator (Ovodyne, settings: $30 \mathrm{~V}$, 5 pulses $50 \mathrm{~ms}$ wide in a $1 \mathrm{~s}$ interval). Shell windows were sealed with Parafilm (Pechiney Plastic Packaging) and incubated at $38^{\circ} \mathrm{C}$ until harvesting at $\mathrm{HH}$ st. $28 / 29$. The efficiency of electroporation varied between $5 \%$ and $30 \%$ of total LMC neurons electroporated depends upon the construct and DNA concentration used. When the nontagged expression plasmids was coelectroporated with GFP expression plasmids or other plasmids fused with GFP, their concentration was at least three times that of those GFP-fused plasmids to ensure high efficiency of coexpression.

siRNA duplex oligonucleotides with 3'TT overhang were purified over MicroSpin G-25 columns (GE Healthcare) in $10 \mathrm{mM}$ Tris-Cl (Fisher Scientific), $1 \mathrm{mM}$ EDTA (Invitrogen), and $20 \mathrm{mM} \mathrm{NaCl}$ (EMD Chemicals). GFP expression plasmid $(1 \mu \mathrm{g} / \mu \mathrm{l})$ was coelectroporated with the siRNA solution to label motor axons. SiRNA sequences (sense strand) are as follows: [ $\alpha 2$-chi] siRNA, 1:1:1 mixture of GCUCUGACCUUGUUCGAUA, GGAACCUACACUUUGGCAU and CCAGAUGAACAGCUGGAAA.

\section{Cholera toxin-B retrograde labeling of motor neurons}

To identify motor neurons innervating extensor and flexor muscles, injections of Alexa Fluor-conjugated cholera toxin B subunit (CtB; Invitrogen) were made into the muscular layers of the vastus lateralis (Alexa Fluor-488-Ctb) and bicep femoris (Alexa Fluor-594-Ctb), respectively. Mice were anesthetized with isofluorane (2-3\%) and once a deep level of anesthesia was obtained (failure to withdraw from footpinch), a $2 \mu \mathrm{l}$ injection of $0.5 \%$ Alexa-Ctb was made into $1-2$ sites along each muscle. Injections were performed at a rate of $0.5 \mu \mathrm{l} / \mathrm{min}$ using a Hamilton syringe with a 30.5 gauge injection needle. Animals were killed $2 \mathrm{~d}$ after tracer injection by ketamine/xylazine terminal anesthesia using perfusion fixation (PBS followed by 4\% PFA). The L2-L5 segments of the lumbar spinal cord were identified by vertebrae counts, dissected, and postfixed overnight in $4 \% \mathrm{PFA}$ at $4^{\circ} \mathrm{C}$. Then, $50 \mu \mathrm{m}$ vibratome sections were serially collected and mounted in Fluoromount-G (Southern Biotech).

\section{Motor neuron position assignment and quantification}

A total of 10 animals/genotype/age were injected and analyzed. All quantifications were done on at least 5 consecutive sections from lumbar levels L2-L5 and at least 160 cells/genotype/age were quantitated. To identify motor neuron position, normalized spinal cord landmarks were assigned values to establish a common X-Y coordinate system for labeled motor neurons cell bodies. For mediolateral assignment, the central canal was set as the 0 coordinate and the most lateral edge of the spinal cord section was set as the 1 coordinate. For dorsoventral assignment, the central canal was set as the 1 coordinate and the most ventral edge of the spinal cord section was set as the 0 coordinate. ML and DV positions were calculated using ImageJ software. Dataset visualization and statistical analysis was performed using R (R Foundation for Statistical Computing, http://www.r-project.org). One-dimensional kernel density estimates were obtained using the R "density" function. One-dimensional data were compared using unpaired Student's $t$ test. Two-dimensional kernel density estimation used to compute the distribution contours was obtained using the "kde2d" function provided in the "MASS" library. Twodimensional kernel density estimations were graphically displayed as contour plots and were compared using a two-sample Hotelling's T2, which is a two-dimensional generalization of the Student's $t$ test. For box plots, the horizontal bar indicates the median value, box limits are set at the 25 th and 75 th percentile of the distribution, whiskers are set for the minimum and maximum data points.

\section{In situ mRNA detection and immunostaining}

Chick and mouse embryos were fixed in a $4 \%$ solution of paraformaldehyde (Sigma) in PBS, equilibrated with 30\% sucrose in PBS, embedded in optimal cutting temperature medium (Sakura Finetek), and stored at $-80^{\circ} \mathrm{C}$. Twelve-micrometer sections were collected using a Leica cryostat microtome.

In situ mRNA detection was performed as described previously (Schaeren-Wiemers and Gerfin-Moser, 1993; Kania and Jessell, 2003a). In brief, tissue sections were first fixed in $4 \%$ solution of paraformaldehyde in PBS for 10 min at room temperature (RT), washed three times with PBS for $5 \mathrm{~min}$, and digested in Proteinase K solution $(1 \mu \mathrm{g} / \mathrm{ml}$; Roche) in 6.25 mM EDTA, pH 8.0 (Invitrogen) and $50 \mathrm{mM}$ Tris pH 7.5 (Fisher Scientific). Samples were acetylated for $10 \mathrm{~min}$ by immersion in a mixture of $6 \mathrm{ml}$ of triethanolamine (Sigma), $500 \mathrm{ml}$ of double-distilled $\mathrm{H}_{2} \mathrm{O}$, and $1.30 \mathrm{ml}$ of acetic anhydride (Sigma). After PBS washes, samples were incubated with hybridization buffer [ $50 \%$ formamide, $5 \times$ SSC $(20 \times \mathrm{SSC}$ is $3 \mathrm{M} \mathrm{NaCl}, 0.3 \mathrm{M} \mathrm{NaAc}), 5 \times$ Denhardts (Sigma), and 500 $\mu \mathrm{g} / \mathrm{ml}$ salmon sperm DNA (Roche)] for $2 \mathrm{~h}$ at RT, followed by incubation overnight at $72^{\circ} \mathrm{C}$ with DIG-labeled RNA probes (see above) in the hybridization buffer at a concentration of $2-5 \mathrm{ng} / \mu \mathrm{l}$. After hybridization, samples were immersed in $5 \times$ SSC at $72^{\circ} \mathrm{C}$, followed by 2 washes in $0.2 \times$ $\mathrm{SSC}$ at $72^{\circ} \mathrm{C}$ for $45 \mathrm{~min}$ each and $0.2 \times \mathrm{SSC}$ at RT for $5 \mathrm{~min}$. Tissues were then rinsed with B1 buffer (0.1 M Tris, pH 7.5, and $0.15 \mathrm{M} \mathrm{NaCl}$; Fisher Scientific) for $5 \mathrm{~min}$, blocked with B2 buffer (10\% heat-inactivated horse serum in B1) for $1 \mathrm{~h}$ at RT, and incubated with anti-DIG antibody (1: 5000 in B2; Roche) overnight at $4^{\circ} \mathrm{C}$. Samples were then rinsed with B1 and equilibrated with B3 buffer (0.1 M Tris, pH 9.5, 0.1 M NaCl, 0.05 M $\mathrm{MgCl}_{2}$; Fisher Scientific). To detect bound anti-DIG antibodies, samples 
were incubated with B4 buffer (100 mg/Ml NBT, 50 mg/Ml BCIP; Roche) and $400 \mathrm{~mm}$ levamisole (Sigma) in B3 in the dark. The reaction was stopped by immersion in $\mathrm{H}_{2} \mathrm{O}$.

For immunostaining, sectioned tissue was first washed in PBS, incubated in blocking solution ( $1 \%$ heat-inactivated horse serum in $0.1 \%$ Triton-X/PBS; Sigma) for $5 \mathrm{~min}$, followed by incubation overnight at $4^{\circ} \mathrm{C}$ in selected primary antibodies diluted in blocking solution. The following primary antibodies were used: guinea pig and mouse anti-Isl1 (1:1000 and 1:100; Tsuchida et al., 1994b), rabbit anti-Lim1/2 (1:100; Tsuchida et al., 1994b), rabbit anti-FoxP1 (1:1000; Abcam), guinea pig anti-FoxP1 (1:1000; Dasen et al., 2008), sheep anti-GFP (1:1000; Invitrogen), rabbit anti-EphA4 (1:1000; Santa Cruz Biotechnology), goat anti-EphB1 (1: 500; Santa Cruz Biotechnology), mouse anti-mouse $165 \mathrm{kDa}$ neurofilament (1:500; Dodd and Jessell, 1988). After incubation in the primary antibodies, samples were washed with PBS and incubated with appropriate secondary antibodies for $1 \mathrm{~h}$ at RT. The following secondary antibodies were used: Cy3- (or Cy-5)-conjugated AffiniPure donkey anti-mouse (rabbit, goat, or guinea pig) IgG (1:1000 for Cy3, 1:500 for Cy5 secondary antibodies; Jackson ImmunoResearch Laboratory), Alexa Fluor 488 donkey anti-mouse (rabbit or sheep) IgG (1:1000; Invitrogen).

\section{Coimmunoprecipitation}

Spinal cords from postnatal day 3 (P3) wild-type mice were acutely isolated and homogenized in lysis buffer (25 mM Tris, pH 7.5, $150 \mathrm{mM}$

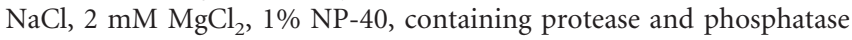
inhibitors). After 30 minutes on ice, lysates were clarified by centrifugation and incubated with $3 \mu \mathrm{g}$ of anti- $\alpha 2$-chimaerin or negative control anti-HA antibodies for $3 \mathrm{~h}$ at $4^{\circ} \mathrm{C}$, followed by incubation with protein $\mathrm{A} / \mathrm{G}$ magnetic beads (Pierce) for $1 \mathrm{~h}$ at room temperature. The beads were washed three times with lysis buffer and bound proteins were eluted and analyzed by SDS-PAGE and immunoblotting. The following antibodies were used: rabbit anti- $\alpha 2$-chimaerin (Abcam), rabbit anti-HA (Abcam), rabbit anti-EphB1 (Santa Cruz Biotechnology), and goat anti-EphA4 (R\&D Systems).

\section{Image quantification}

Images were acquired using a Leica DM6000 microscope; Zeiss LSM or Nikon A1R confocal microscope with Volocity imaging software (Improvision). GFP-labeled axonal projections were quantified by combining over threshold pixel counts in limb section images containing limb nerves (10-15 of 12 micrometer limb sections from each embryo) using Photoshop (Adobe). The dorsal or ventral limb nerve was selected by gating on the neurofilament channel and using the lasso tool, and pixel counts from the threshold to the maximal level were those indicated in the histogram window of the GFP channel. Motor neuron numbers were quantified by combining cell counts of a series of spinal cord section images (5-10 of $12 \mu \mathrm{m}$ limb sections from each embryo).

\section{Behavioral experiments}

Adult male mice 10-12 weeks of age were used for all behavioral tests ( $n=20$, 10 wild-type, $10 \alpha 2$-chimaerin ${ }^{g t / g t}$. Homozygous $\alpha 2$-chimaerin gene-trap and wild-type (C57BL/6J) littermate controls were used for all behavioral experiments. All animals were kept on a 12:12 light dark cycle and tested during the light phase. All animal procedures were approved and performed in compliance with the University of Michigan Institutional Animal Care and Use Committee, in accordance with the standards in the National Institutes of Health's Guide for the Care and Use of Laboratory Animals. Statistical analysis was performed using GraphPad Prism 6. Results are expressed as mean $\pm \mathrm{SD}$ with significance defined a $p<0.05$, Student's $t$ test.

Digigait. Gait analysis was performed using a digital footprint analysis system (DigiGait; Mouse Specifics). Adult male mice were accustomed to the motorized transparent treadmill at gradually increasing speeds and recorded at $20 \mathrm{~cm} / \mathrm{s}$. A high-speed video recorder mounted underneath the belt was used to image the ventral side of the mice and recorded at least six complete steps. Videos were acquired with DigiGait Video Imaging Acquisition software and analyzed with DigiGait Video Imaging Analysis Software.

Accelerating rotarod. The rotarod apparatus (Ugo Basile) was composed of a horizontal rod, $3 \mathrm{~cm}$ in diameter, separated by opaque plastic dividers to accommodate up to 5 mice per trial. Adult male mice were trained for 2 consecutive days ( 3 trials per day) and tested on the third day. Each trial started at a speed of $4 \mathrm{rpm}$ and slowly accelerated to 40 rpm over the course of $300 \mathrm{~s}$. The latency to fall from the rod was recorded and data are reported as the average of 3 trials on test day (day 3 ). Rest periods in between trials were at least $5 \mathrm{~min}$.

Open field. Locomotor activity was measured with Photobeam Activity System-Open Field (San Diego Instruments). Each animal was tested for $60 \mathrm{~min}$ in a $16 \times 16$ clear acrylic animal enclosure with both horizontal and vertical photobeams. Data were collected by the PAS software. Each chamber was rinsed with water, followed by $70 \%$ alcohol, and allowed to air dry between animals. Four chambers ran simultaneously.

Grid hang. Mice were placed on a wire grid (mouse cage lid) $40 \mathrm{~cm}$ above a padded surface, which was slowly inverted to let the mice hang by their paws. Mice were timed until they fell off, up to 120 s. Mice were given three trials and the best trial was recorded. It was also recorded if the mice exhibited any hyperflexion behavior during the grid hang test.

\section{Statistical analysis}

Data from the experimental replicate sets were evaluated using Microsoft Excel, Aabel (Gigawiz), or Prism (GraphPad). Means of the combined proportions or cell numbers were compared with Student's unpaired $t$ tests with the threshold for statistical significance set at 0.05 . For multiple comparisons, one-way ANOVA with Tukey post hoc was used and statistical significance was set at 0.05 .

\section{Results}

\section{$\alpha 2$-chimaerin is expressed in LMC neurons}

To examine the functional role of $\alpha 2$-chimaerin in Eph receptordependent spinal motor neuron signaling, we first surveyed its expression in LMC neurons in which EphA and EphB class signaling plays a prominent role in axon guidance. We thus examined $\alpha 2$-chimaerin mRNA expression by in situ hybridization in both brachial/cervical and lumbar spinal cord sections of e11.5 mouse embryos and lumbar spinal cord of HH st. 25/26 chick embryos at the time of LMC axon growth into the limb mesenchyme (Fig. 1 and data not shown; Tosney and Landmesser, 1985; Hamburger and Hamilton, 1992; Kania et al., 2000). LMC neurons were identified by their expression of the medial LMC neuron marker Isll and the lateral LMC neuron marker Lim1 (Fig. 1A, B, D,E; Tsuchida et al., 1994b). $\alpha 2$-chimaerin mRNA was highly expressed in both medial and lateral LMC motor neurons in chick and mouse embryos without any apparent enrichment in either LMC neuron subpopulation (Fig. 1C,F).

To determine whether $\alpha 2$-chimaerin interacts with Eph receptors in vivo, spinal cord lysates from $\mathrm{P} 3$ wild-type mice were immunoprecipitated with an anti- $\alpha 2$-chimaerin antibody or negative control anti-HA antibody. Both EphA4 and EphB1 were coimmunoprecipitated with $\alpha 2$-chimaerin (Fig. 1G). Together, these data demonstrate that $\alpha 2$-chimaerin is broadly expressed in LMC motor neuron pools and can interact with both EphA4 and EphB1 receptors, critical mediators of lateral and medial LMC axonal pathfinding, respectively.

\section{$\alpha 2$-chimaerin is required for ephrin-A-mediated motor axon responses in vitro}

To investigate directly the dependence of Eph signaling on $\alpha 2$ chimaerin function, we tested the response of LMC axons to stripes of ephrin-A or ephrin-B proteins in the context of $\alpha 2$-chimaerin loss or gain of function (Kao and Kania, 2011). We electroporated inhibitory siRNAs against $\alpha 2$-chimaerin mRNA ([ $\alpha 2$-chi $]$ siRNA), expression plasmids encoding a full-length untagged $\alpha 2$-chimaerin $(\alpha 2$-chi), GFP-tagged $\alpha 2$-chimaerin ( $\alpha 2$-chi::GFP), or GAP-domain-inactive mutant $\left(\alpha 2-c h i^{\triangle Y R V}:: G F P\right)$, which severely attenuates Rac1 inhibition, into chick HH st. 18/19 LMC neurons (Fig. 2; Hall et al., 

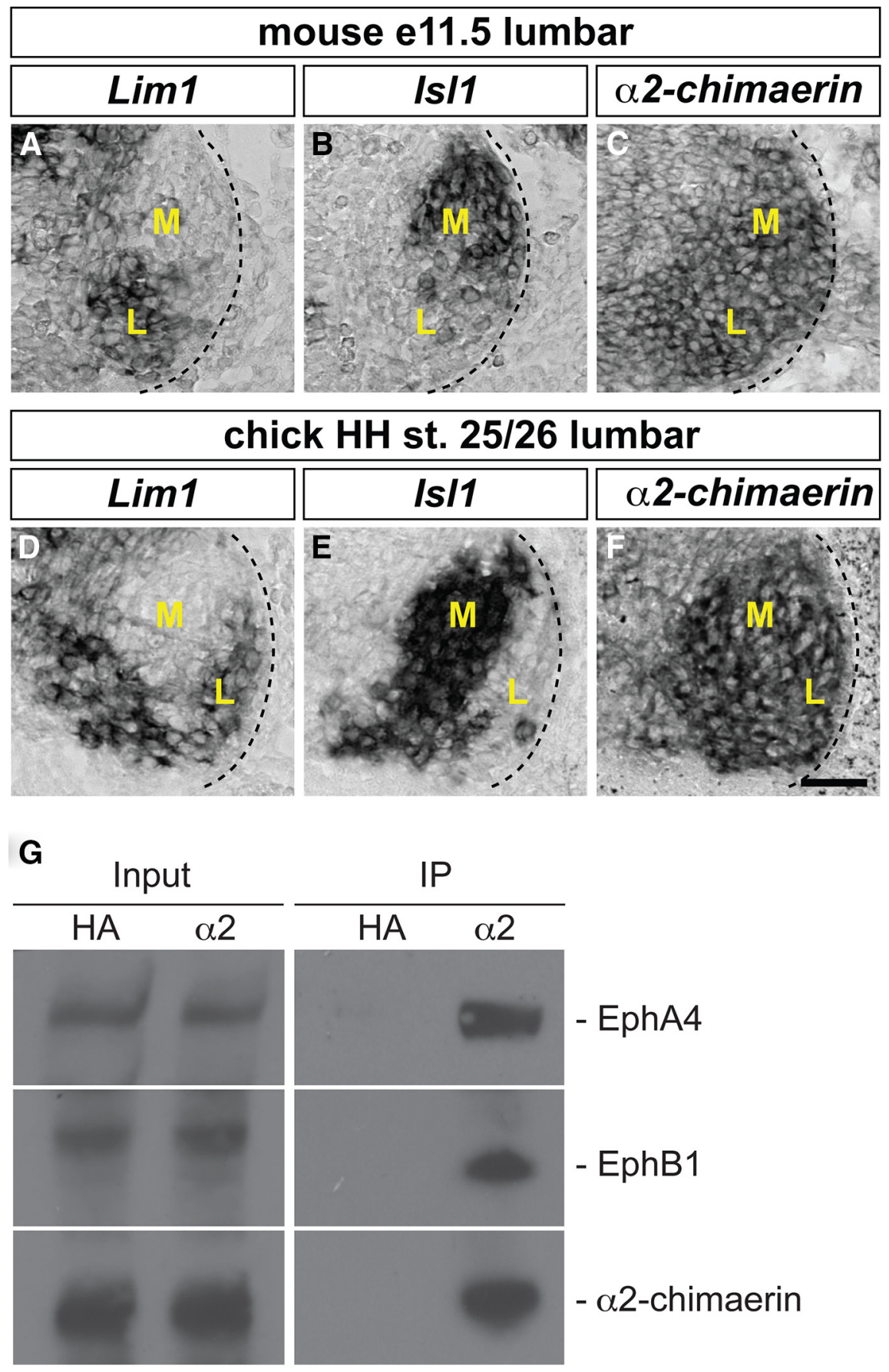

Figure 1. Expression of $\alpha 2$-chimaerin in LMC motor neurons. $\boldsymbol{A}-\boldsymbol{F}$, Detection of mRNA in consecutive sections of the spinal cord. All mouse sections $(\boldsymbol{A}-\boldsymbol{C})$ are from e11.5 lumbar spinal cord; all chick sections $(\boldsymbol{D}-\boldsymbol{F})$ are from HH st. 25/26 lumbar spinal cord. $\boldsymbol{A}$, $\boldsymbol{B}$, Detection of $\operatorname{Lim} 1(\boldsymbol{A})$ and $/ s / 1(\boldsymbol{B}) \mathrm{mRNA}$ in lateral and medial LMC neurons, respectively, in the mouse spinal cord. Dark pixels denote high signal. C, Detection of $\alpha 2$-chimaerin mRNA in both medial and lateral mouse LMC neurons. D, E, Detection of Lim 1 (D) and $/ s / 1(\boldsymbol{E}) \mathrm{mRNA}$ in lateral and medial chick LMC neurons, respectively. $\boldsymbol{F}$, Detection of $\alpha$-chimaerin mRNA in both medial and lateral chick LMC neurons. M, Medial; L, lateral. Scale bars in $\boldsymbol{A}-\boldsymbol{F}, 50 \mu \mathrm{m} . \mathbf{G}, \alpha 2$-chimaerin interacts with EphA4 and EphB1 in mouse spinal cord. Lysates from wild-type $\mathrm{P} 3$ mouse spinal cord were immunoprecipitated with anti- $\alpha 2$-chimaerin antibody or anti-HA antibody (negative control). Bound and total proteins were analyzed by immunoblotting with antibodies against EphA4, EphB1, $\alpha 2$-chimaerin. Input represents a 1\% aliquot of the total load.

2001). After incubation, HH st. 25/26 LMC explants were dissected and placed onto carpets of two alternating stripes: those containing a mixture of ephrin-Fc and a Cy3 secondary antibody or Fc and $\mathrm{Cy} 3$ secondary antibody and those containing Fc protein only. Medial LMC axons were identified by e[Isl1]::GFP electroporation, whereas lateral LMC axons were identified by their
EphA4 expression and stripe preference was scored as the proportion of GFP or EphA4 signal found over the different stripes after overnight explant culture (Kao and Kania, 2011).

Medial LMC neurons coexpressing $e[$ Isl1]::GFP and [ $\alpha 2-c h i] s i R N A$ or $\alpha 2-$ chimaerin $(\alpha 2-c h i)$ exhibited normal avoidance of ephrin-B2/Fc stripes compared with controls expressing e[Isl1]::GFP only (Fig. $2 A-C ; p=0.107$ for $\alpha 2$-chi and 0.283 for $[\alpha 2-c h i] \operatorname{siRNA})$, suggesting that $\alpha 2$ chimaerin does not play an important role in ephrin-B-mediated medial LMC axon guidance in vitro. In contrast, lateral LMC neurons electroporated with $[\alpha 2-c h i]$ siRNA and a GFP expression plasmid or a plasmid encoding the GAP-inactive mutant $\alpha 2$ $c h i^{\Delta Y R V}:: G F P$ exhibited significantly attenuated repulsion from ephrin-A5 stripes compared with GFP controls, suggesting that $\alpha 2$-chimaerin and its GAP activity is required for EphA-mediated lateral LMC axon repulsion from ephrin-A5 (Fig. $2 D-G$; $p<0.001$ for both groups). Similarly, lateral LMC neurons expressing the wild-type fusion protein $\alpha 2$-chi::GFP showed attenuated repulsion from ephrinA5 compared with GFP controls (Fig. 2F). Together, these data demonstrate that gain or loss of function of $\alpha 2$-chimaerin yield similar axon guidance defects, suggesting that the accuracy of signaling in response to ephrin-As is critically dependent upon the spatially restricted pool of activated $\alpha 2$-chimaerin (Fig. 2E,F; $p<$ 0.01). Supporting this model, hyperactivating and loss-of-function mutations in $\alpha 2$ chimaerin that respectively decrease or increase Rac1 signaling cause axon guidance defects in humans and in mouse and zebrafish models (Beg et al., 2007; Iwasato et al., 2007; Wegmeyer et al., 2007; Miyake et al., 2008; Clark et al., 2013). These results demonstrate that $\alpha 2$-chimaerin is essential for lateral LMC axon repulsion from ephrin-A, but not for medial LMC repulsion from ephrin-B.

\section{$\alpha 2$-chimaerin function is required for} EphA signaling in LMC axons in vivo Ectopic expression of EphA and B receptors in LMC neurons is sufficient to redirect their axonal trajectory in vivo: EphA4 redirects LMC axons dorsally, while EphB redirects axons ventrally (Fig. $3 B, D$; Eberhart et al., 2002; Kania and Jessell, 2003; Luria et al., 2008). We hypothesized that, if $\alpha 2$-chimaerin is required for EphA signaling, then in vivo redirection of LMC trajectory by EphA overexpression should be attenuated by the loss of $\alpha 2$-chimaerin. To test this idea, we coelectroporated chick HH St. 18/19 LMC neurons with various Eph receptor and $\alpha 2$ chimaerin 


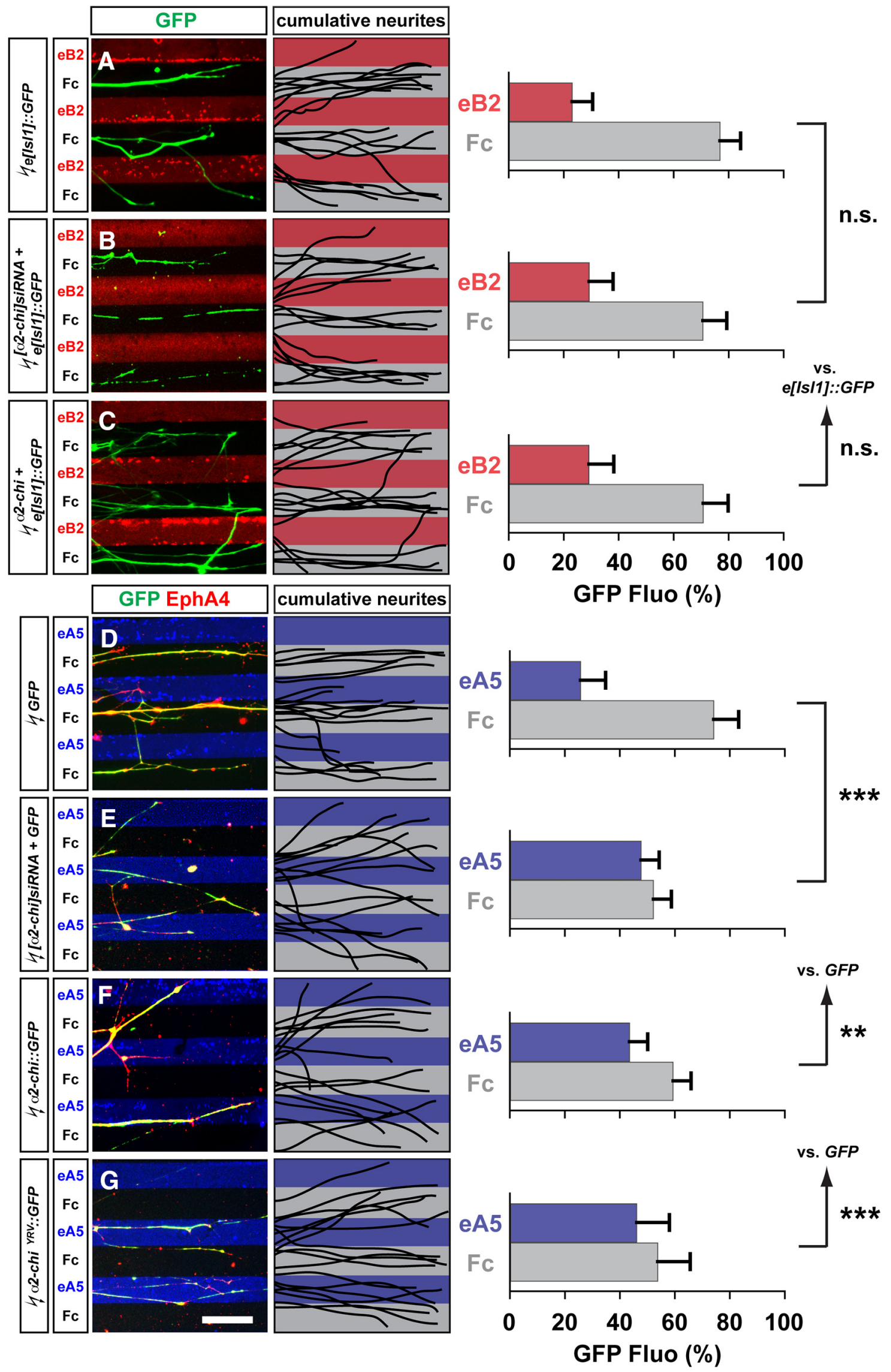

Figure 2. $\quad \alpha 2$-chimaerin function is required for EphA forward signaling in cultured LMC neurons. $A-C$, Detection of medial $\left(G F P^{+}\right)$LMC neurites of e[/s/1]]::GFP $(A),[\alpha 2-c h i] s i R N A+e[/ s / 1]$ : GFP $(\boldsymbol{B})$, or $\alpha 2$-chi $+e[/ / / 1]$ ::GFP $(\boldsymbol{C})$ on ephrinB2-Fc/Fc stripes and superimposed images of five representative explants from each experimental group highlighting (Figure legend continues.) 

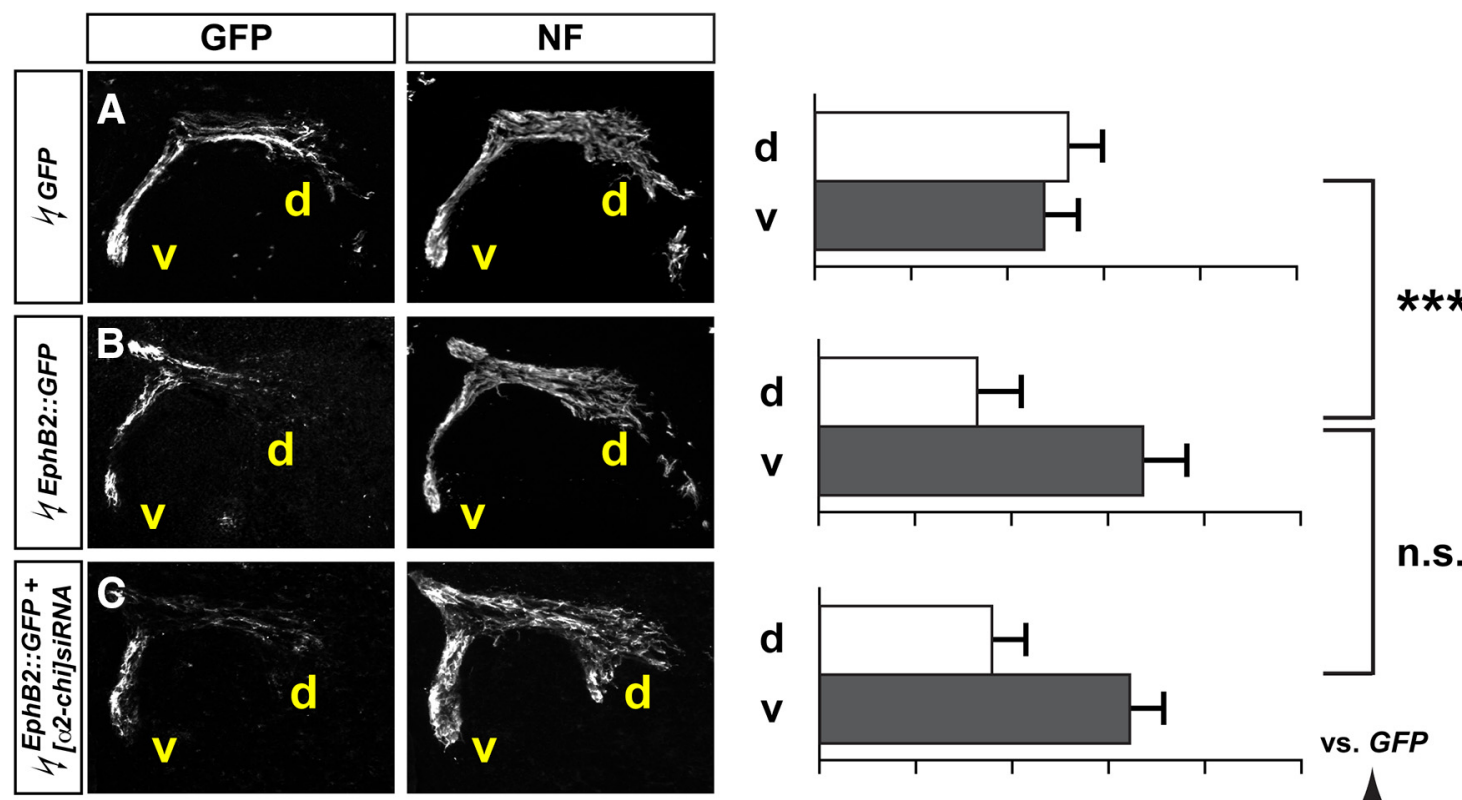

n.s.
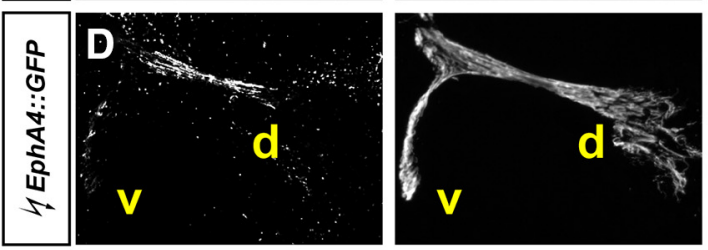

\section{d
v}

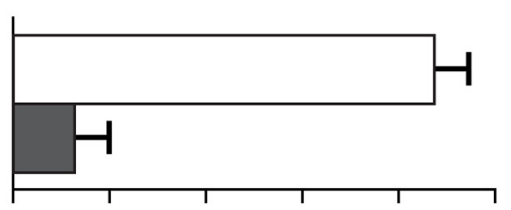
vs. GFP
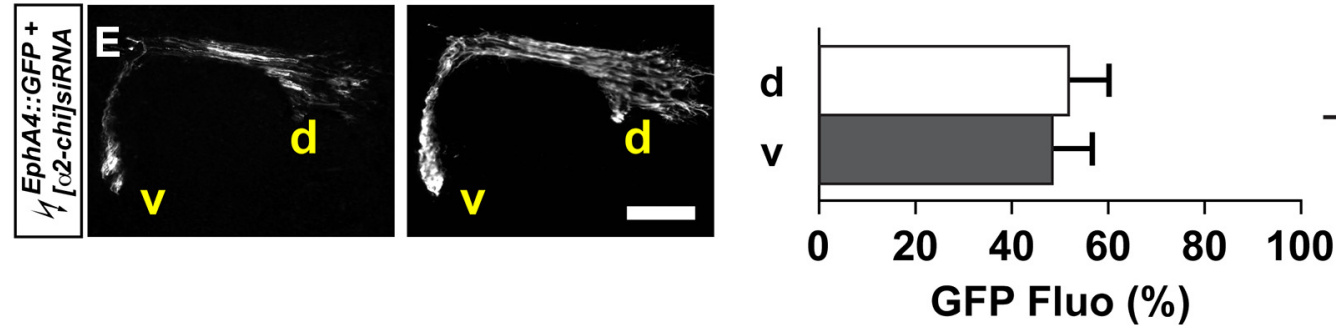

$* * *$

Figure 3. $\alpha 2$-chimaerin loss attenuates EphA4, but not EphB2-induced LMC motor axon redirection in vivo. All images are at chick HH st. 28/29 lumbar levels. $\boldsymbol{A}-\boldsymbol{E}$, GFP and neurofilament

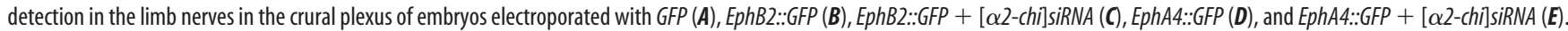
Quantification of GFP signals in both groups expressed as, respectively, percentage in dorsal and ventral limb nerves [GFP Fluo (\%)]. Number of embryos: $n=5$ for all groups. Scale bars in $\boldsymbol{A}-\boldsymbol{D}, 150 \mu \mathrm{m}$.

expression plasmids and determined the proportion of $\mathrm{GFP}^{+}$ axons entering the dorsal and ventral limb nerve branches at HH st. 28/29 (Kao and Kania, 2011). Specifically, we coelectroporated the Eph receptor-GFP fusion protein expression plasmid EphB2::GFP or EphA4::GFP with [ $\alpha 2$-chi] siRNA and compared with control EphB2::GFP or EphA4::GFP plasmid electroporation. Ectopic EphB2::GFP and EphA4::GFP expression induced a redirection of LMC axons into the ventral and dorsal limb nerves, respectively (Fig. $3 A, B, D ; p<0.001$ for both groups vs GFP

\footnotetext{
(Figure legend continued.) the distribution of LMC neurites. Quantification of medial (GFP ${ }^{+}$) LMC neurites on first (red) and second (pale) stripes expressed as a percentage of total GFP signals. Minimal number of neurites and explants: 79 and 11 for all groups. $\mathbf{D}-\mathbf{G}$, Detection of lateral $\left(\mathrm{EphA4}^{+}{ }^{+}\right)$LMC neurites of GFP $(\boldsymbol{D}),[\alpha 2$-chi] $]$ siRNA + GFP $(\boldsymbol{E}), \alpha 2$-chi::GFP $(\boldsymbol{F})$, or $\alpha 2$-chi ${ }^{\triangle Y Y V}:: G F P(\mathbf{G})$ on ephrinA5-Fc/Fcstripes and superimposed images of five representative explants from each experimental group highlighting the distribution of LMC neurites. Quantification of electroporated lateral (EphA4 ${ }^{+}$) LMC neurites on first (blue) and second (pale) stripes expressed as a percentage of total EphA4 signals. Minimal number of neurites and explants: 72 and 10 for all groups. eB2, ephrin-B2; eA5, ephrin-A5. Error bars indicate SD. ${ }^{* * *} p<0.001 ;{ }^{* *} p<0.01$; n.s., not significant; statistical significance computed using Student's unpaired $t$ test; all values are mean \pm SD. Scale bars in $\boldsymbol{A}-\mathbf{G}, 50 \mu \mathrm{m}$.
}

$\leftarrow$ controls). In embryos coelectroporated with EphB2::GFP and [ $\alpha 2$-chi] siRNA, proportions of GFP signals observed in the limb nerve branches were similar to that seen in embryos overexpressing EphB2::GFP alone (Fig. $3 B, C ; p=0.251$ ). In embryos coelectroporated with EphA4::GFP and [ $\alpha 2$-chi]siRNA, however, proportions of GFP signals were significantly increased in ventral branches compared with EphA4::GFP electroporated controls (Fig. 3D, E; $p<0.001$ ), consistent with the loss of $\alpha 2$ chimaerin attenuating EphA4-induced, but not EphB2-induced, LMC motor axon redirection. These observations argue that, in vivo, normal $\alpha 2$-chimaerin protein levels are required for EphA receptor, but not EphB receptor, signal relay.

Cell-autonomous requirement for $\alpha 2$-chimaerin in the selection of limb trajectory by LMC axons

To assess the function of $\alpha 2$-chimaerin in LMC axon trajectory choice in vivo, we coelectroporated [ $\alpha 2$-chi] siRNA and a GFP plasmid in chick embryos (Fig. 4A-F; Kao and Kania, 2011). In situ hybridization of spinal cord sections revealed that $[\alpha 2-$ chi] siRNA delivery effectively knocks down $\alpha 2$-chimaerin mRNA (Fig. $4 C, F, G$ ). Importantly, $\alpha 2$-chimaerin knock down did not cause a significant change in the number or type of LMC motor 

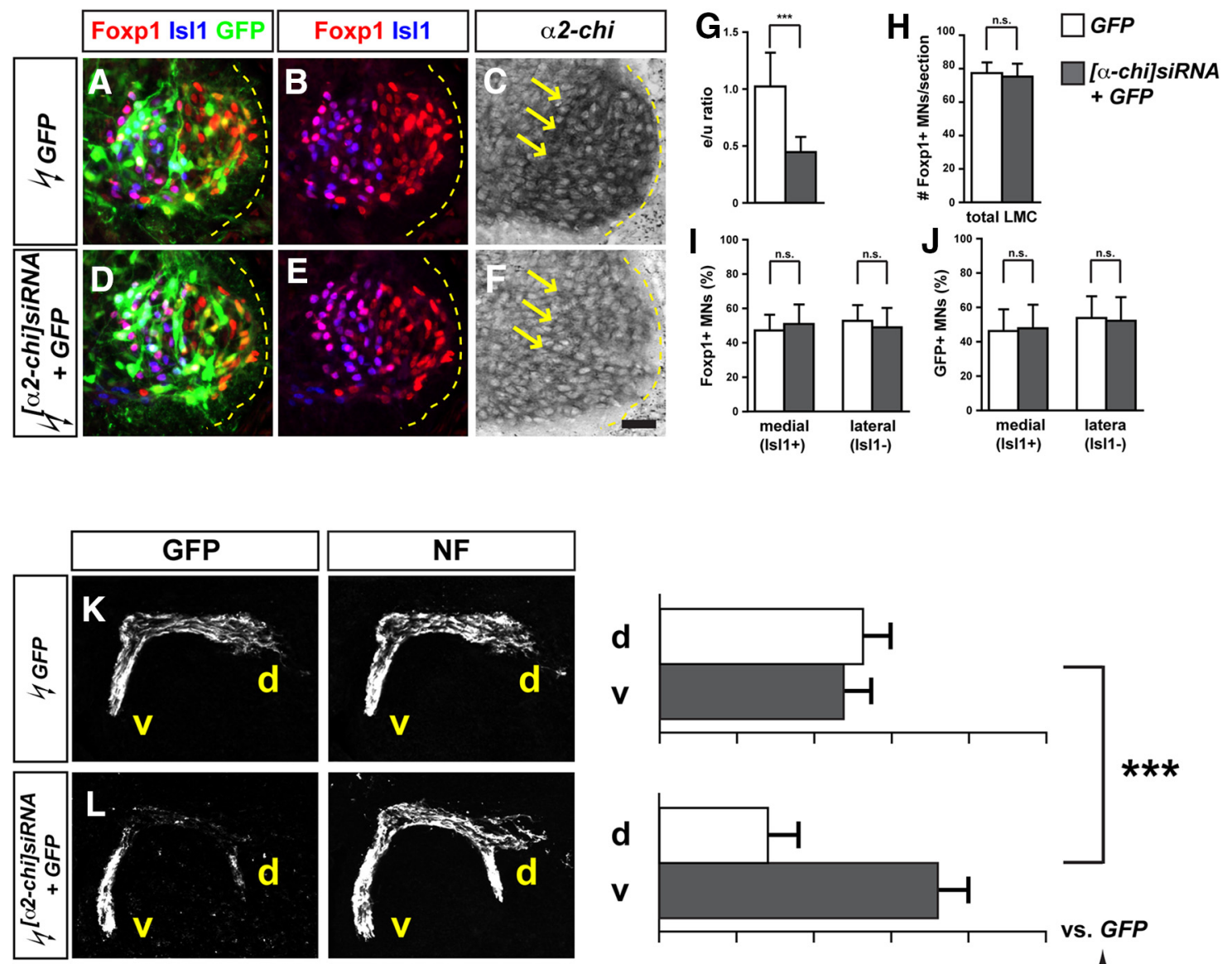

$* * *$
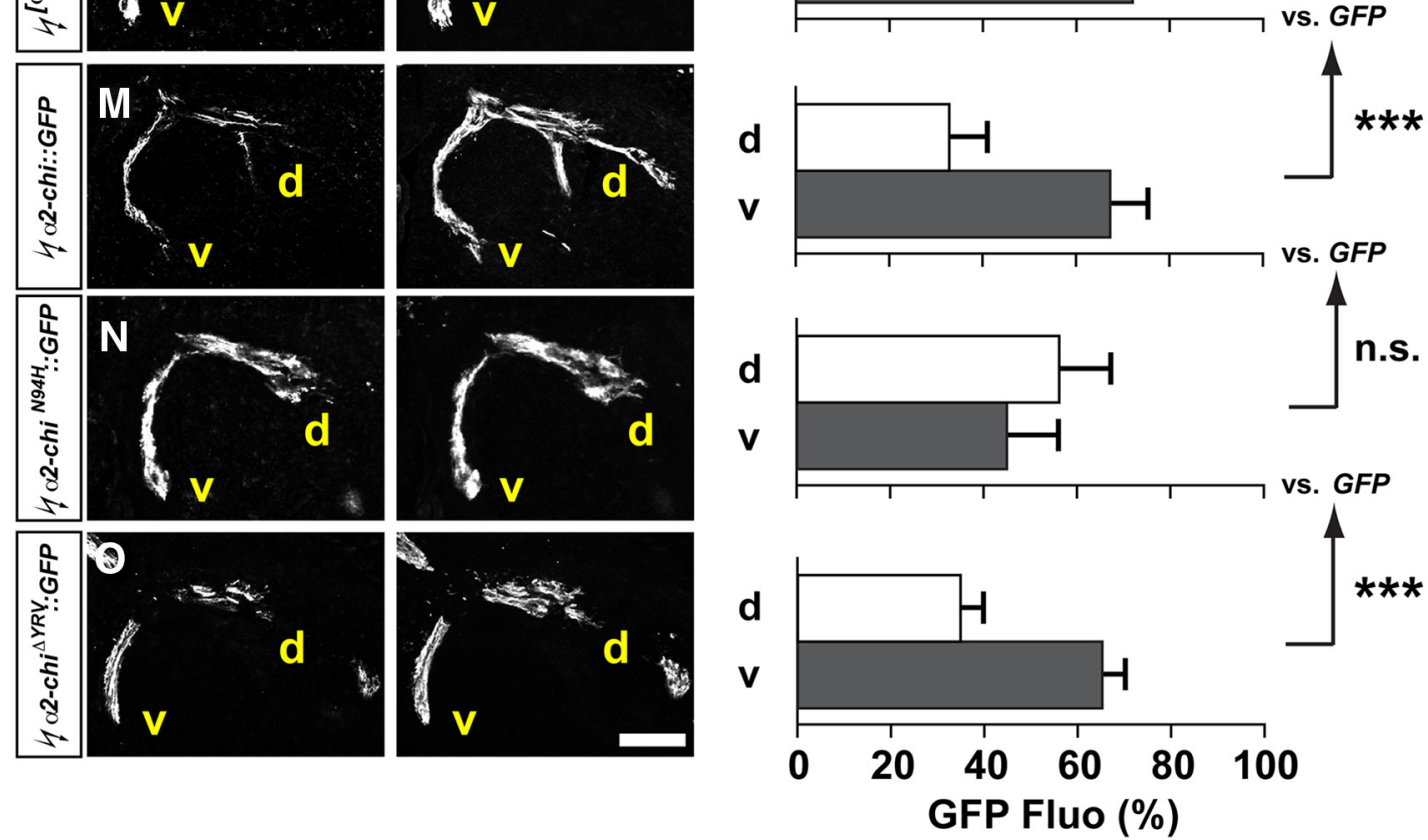

Figure 4. Cell-autonomous function of $\alpha 2$-chimaerin in LMC axon guidance in the limb. $A-F$, Detection of Foxp1, Isl1, GFP, and $\alpha 2$-chimaerin mRNA in LMC neurons of chick HH st. $28 / 29$ embryos electroporated with GFP $(\boldsymbol{A}-\boldsymbol{C})$ and $[\alpha 2$-chi]siRNA + GFP $(\boldsymbol{D}-\boldsymbol{F})$. G, Quantification of effects of GFP and [ $\alpha 2$-chi]siRNA + GFP electroporation on $\alpha 2$-chimaerin mRNA levels. The ratio of immunoreactivity signal levels in LMC neurons, of the electroporated to the contralateral side (e/u ratio), was obtained in at least 16 sections of 5 embryos (Kania and Jessell, 2003 ). $\boldsymbol{H}$, Number of LMC motor neurons expressed as the average number of total (Foxp $1^{+}$) LMC neurons per section (\#Foxp $1^{+} /$section). $I, J$, Number of total or electroporated medial (Foxp $1^{+}|s| 1^{+}$) and lateral $\left(\right.$ Foxp $\left.1^{+}|\mathrm{s}| 1^{-}\right)$LMC motor neurons in lumbar spinal cord expressed as the percentage of total motor neurons [Foxp ${ }^{+}$MNs (\%)] $(\boldsymbol{I})$ or electroporated motor neurons [GFP ${ }^{+}$MNs $\left.(\%)\right](J) . K-L, G F P$

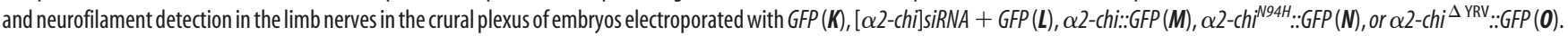
Quantification of GFP signals in both groups expressed as, respectively, percentage in dorsal and ventral limb nerves [GFP Fluo (\%)]. Number of embryos: $n=5$ for all groups. All images are at chick HH st. $28 / 29$ lumbar levels. Error bars indicate SD. ${ }^{* *} p<0.001 ;{ }^{* *} p<0.01 ; n$. ., not significant; statistical significance computed using Student's unpaired $t$ test; all values are mean \pm SD. Scale bars in $\boldsymbol{A}-\boldsymbol{F}, 150 \mu \mathrm{m}$. 
neurons (Fig. $4 H-J$ ). After incubation until $\mathrm{HH}$ st. 28/29, we determined the proportion of $\mathrm{GFP}^{+}$axons in the dorsal and ventral limb nerve branches. In $[\alpha 2$-chi] siRNA-expressing embryos, we observed a significantly greater proportion of GFP ${ }^{+}$ axons entering the ventral nerve branches compared with GFP controls (Fig. $4 K, L ; p<0.001$ ). These results are consistent with the above in vitro observations and suggest that the loss of $\alpha 2$ chimaerin from LMC neurons results in a loss of fidelity of limb trajectory choice by lateral LMC axons, and their selection of a ventral limb nerve trajectory.

To determine whether the ectopic expression of $\alpha 2$-chimaerin affected LMC axon trajectory in vivo, we electroporated $\alpha 2$ chimaerin expression plasmids into chick LMC neurons. In embryos expressing wild-type $\alpha 2$-chi::GFP, a significantly increased proportion of $\mathrm{GFP}^{+}$axons were observed in ventral limb nerves compared with GFP controls (Fig. $4 K, M ; p<0.001$ ). To examine the involvement of the $\alpha 2$-chimaerin $\mathrm{SH} 2$ domain, one site of Eph receptor interaction (Beg et al., 2007) and its GAP activity in LMC axon pathfinding, we next electroporated plasmids expressing a GFP-tagged $\alpha 2$-chimaerin $\mathrm{SH} 2$ domain point mutant $\left(\alpha 2-\operatorname{chi}^{N 94 H}:: G F P\right)$ or a GAP inactive mutant $\left(\alpha 2-\operatorname{chi}^{\Delta Y R V}:: G F P\right)$ into chick LMC neurons. Unlike $\alpha 2$-chi::GFP transfected embryos, the proportion of $\mathrm{GFP}^{+}$axons entering the dorsal or ventral limb nerves did not differ from GFP controls in embryos expressing $\alpha 2-c h i^{N 94 H}:: G F P$, implying that the $\mathrm{SH} 2$ domain is critical for the redirection of LMC motor axons (Fig. $4 \mathrm{~K}, \mathrm{~N}$; $p=0.130)$. It is likely that $\alpha 2-c h i^{N 94 H}:: G F P$ expression fails to redirect $\mathrm{LMC}$ axons because $\mathrm{SH} 2$ domain mutations severely attenuate $\alpha 2$-chimaerin-EphA 4 interaction rendering $\alpha 2-$ chi $^{N 94 H}::$ GFP essentially nonfunctional in our assays. In contrast, in embryos expressing a dominant-negative GAP inactive mutant plasmids $\left(\alpha 2-c h i^{\triangle Y R V}:: G F P\right)$, significantly greater proportions of $\mathrm{GFP}^{+}$axons were observed in ventral limb nerves compared with GFP controls (Fig. 4K,O; $p<0.001$ for $\alpha 2-$ chi $\left.^{\Delta \mathrm{YRV}}:: \mathrm{GFP}\right)$. These results suggest that the fidelity of limb trajectory choice by lateral, but not medial, LMC axons depends on cell-autonomous GAP activity of $\alpha 2$-chimaerin.

\section{$\boldsymbol{\alpha} 2$-chimaerin is required for normal lateral LMC axon pathfinding in vivo}

To further ascertain the effects of $\alpha 2$-chimaerin loss on lateral LMC axon pathfinding, we examined the trajectory of genetically tagged lateral LMC axons in $\alpha 2$-chimaerin gene-trapped mutant mice ( $\alpha 2^{g t / g t}$; Beg et al., 2007). $\alpha 2$ mutation did not result in any significant changes in the total number of neurons expressing the LMC marker Foxp1 (Fig. 5I), nor did it cause any change in the proportion of lateral $\left(\right.$ Foxp $\left.1^{+}, \mathrm{Isl}_{1}{ }^{-}\right)$or medial $\left(\right.$Foxp $\left.1^{+}, \mathrm{Isl} 1^{+}\right)$ LMC neurons compared with e12.5 control embryos (Fig. $5 J$ ). In addition, the expression of EphB1 mRNA, and EphA4 receptor protein, both required for normal LMC axon guidance (Helmbacher et al., 2000; Luria et al., 2008), was not affected in $\alpha 2^{\text {gt/gt }}$ mutants and LMC axons entered the dorsal and ventral limb nerves on schedule (Fig. $5 L, P, N, R$; data not shown).

To visualize lateral LMC axons in vivo, we used the transgenic marker line Lim1-IRES-taulacZ ( $\operatorname{Lim} 1^{\mathrm{tlz}}$ ) in which axonally transported LacZ protein is expressed under the control of the lateral LMC neuron marker Lim1 and labels the lateral LMC axonal trajectory in the limb (Kania et al., 2000). In $e 12.5 \alpha 2^{g t / g t}$; $\operatorname{Lim} 1^{\text {tlz/+ }}$ mouse embryos and control $\alpha 2^{g t /+} ; \operatorname{Lim} 1^{\text {tlz/+ }}$ littermates, we analyzed the proportion of LacZ signal in the dorsal and ventral limb nerves by integrating fluorescence intensities of a series of limb section images in multiple embryos (Kania et al., 2000). In $\alpha 2^{\text {gt/gt }} ;$ Lim $1^{\text {tlz/+ }}$ embryos, a significantly greater pro- portion of LacZ-labeled lateral LMC axons was detected in ventral nerves of both hindlimbs and forelimbs compared with $\alpha 2^{g t /+} ;$ Lim $^{\text {tlz/+ }}$ control littermates (Fig. 5S, T; $p<0.001$, data not shown). These observations demonstrate that $\alpha 2$-chimaerin is essential for the fidelity of limb trajectory selection by lateral LMC axons.

\section{LMC axonal miswiring persists in adult $\alpha 2$-chimaerin mutants}

Having demonstrated that $\alpha 2$-chimaerin is required for the accurate guidance of lateral LMC axons in the limb, we next investigated whether the LMC axon trajectory selection errors observed in $\alpha 2^{g t / g t}$ mutant embryos persist to adulthood. The expression of the lateral LMC axon marker $\operatorname{Lim}^{\text {tlz }}$ is extinguished in postnatal animals (Kania et al., 2000). Therefore, to assess the accuracy of LMC axonal projection in postnatal animals, we injected fluorescently labeled cholera toxin-B (Ctb) retrograde tracers into antagonistic flexor and extensor muscles of the mouse thigh and determined the columnar position of labeled LMC cell bodies within the spinal cord as a means of assigning LMC divisional identity (Fig. 6A). We chose two time points at which to assess postnatal connections: $\mathrm{P} 8$, when juvenile mice are not yet walking or bearing their full body weight, and P33, when adult mice are fully ambulatory and mature locomotor stride patterns have been established (Crone et al., 2009). Therefore, in juvenile and adult mice, we unilaterally injected the lateral LMCinnervated vastus lateralis muscle (VL; extensor muscle) with Alexa Fluor 488-conjugated $\mathrm{Ctb}$ and the antagonistic medial LMC-innervated biceps femoris muscle (BF; flexor muscle) with Alexa Fluor 594-conjugated Ctb (Fig. 6A; Jones, 1979; McHanwell and Biscoe, 1981; Tripodi et al., 2011). Dye-injected animals recovered for $2 \mathrm{~d}$ to allow $\mathrm{Ctb}$ to be transported from the muscle injection site to motor neuron cell bodies in positions that were assessed relative to ventral spinal cord landmarks. In wild-type animals at both the P8 and P33 time points, Alexa Fluor 488-Ctblabeled motor neuron cell bodies innervating the VL were positioned lateral relative to the Alexa Fluor 594-Ctb-labeled motor neurons innervating the $\mathrm{BF}$, in agreement with the expected lateral LMC innervation of VL and medial LMC innervation of BF (Fig. 6C-H; Tripodi et al., 2011). In $\alpha 2^{g t / g t}$ mutants, the mediolateral position of Alexa Fluor-488-Ctb-labeled LMC neurons (VL-innervated) was not significantly different from control animals at either time point, suggesting that the majority of labeled lateral LMC neurons appropriately innervate the VL extensor muscle. However, there were a significant number of Alexa Fluor-594-Ctb-labeled motor neuron cell bodies (BF-innervated) within the lateral division of the LMC, intermingled among Alexa488-Ctb+ LMC neurons (Fig. 6B,D,E, G,H, arrowheads). Importantly, we did not observe a significant number of Alexa Fluor-488-Ctb labeled motor neurons (VL-innervated) within the Alexa Fluor-594-Ctb labeled pool (BF-innervated), suggesting that medial LMC neurons do not aberrantly innervate the lateral LMC extensor muscle target VL (Fig. 6D,E,G,H). Together, these data demonstrate that a subset of lateral LMC motor neurons maintain abnormal projections to the BF muscle in early postnatal and adult stage animals.

\section{$\alpha 2$-chimaerin mutants exhibit a hindlimb "hyperflexion" phenotype}

A critical feature of normal locomotion is the coordinated contraction of same-joint flexor and extensor muscles. Although $\alpha 2^{g t / g t}$ mutants exhibit a hopping-gait phenotype, coordinated flexion-extension within the same, and across opposing limbs 

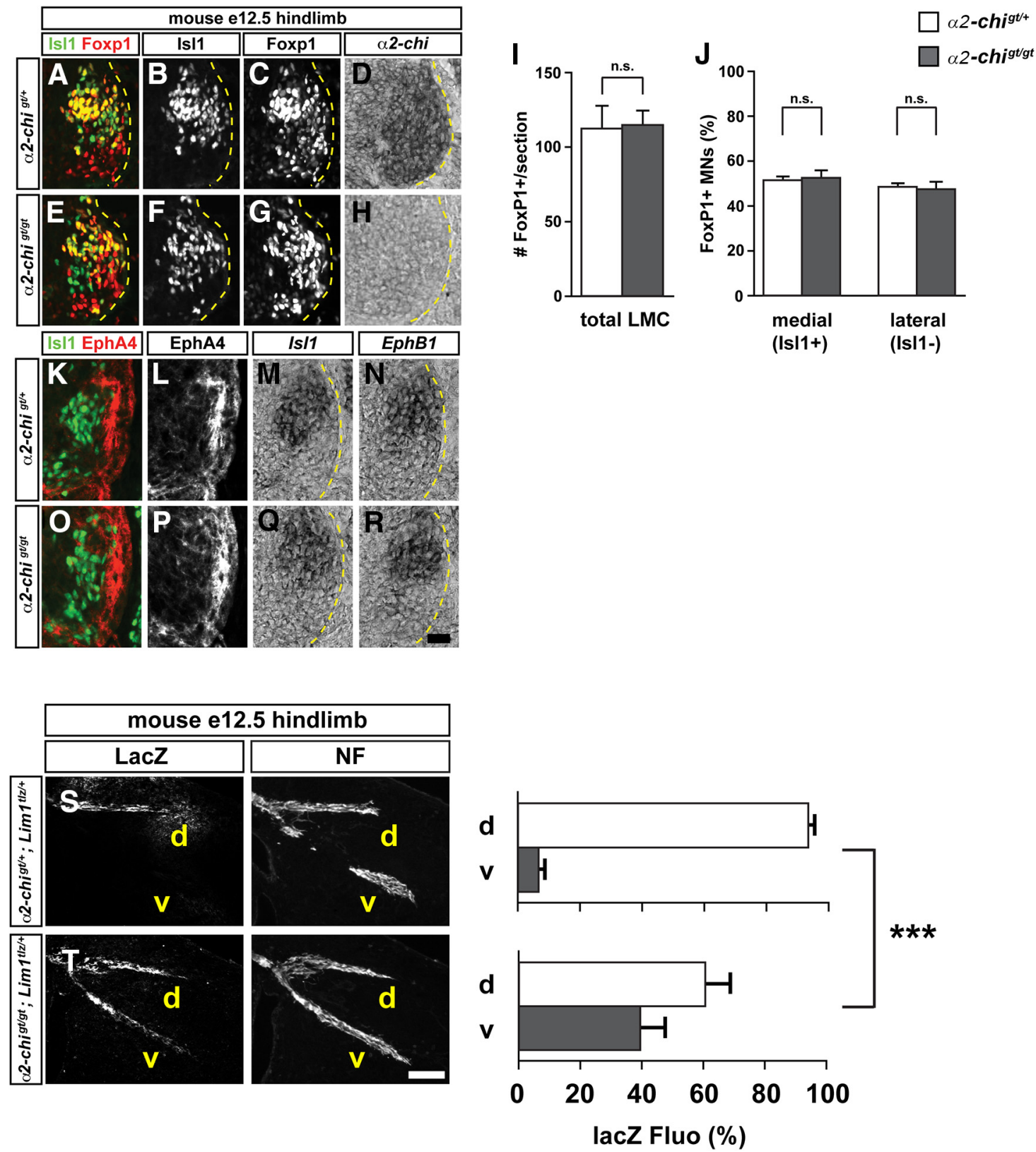

Figure 5. $\alpha 2$-chimaerin is required for the selection of LMC axon trajectory. $\boldsymbol{A}-\boldsymbol{H}$, Detection of I $\mathrm{S} 11$ (green), and Foxp 1 (red) protein and $\alpha 2$-chimaerin mRNA in the LMC region at the lumbar level of control $\alpha 2$-chi ${ }^{g t /+}(\boldsymbol{A}-\boldsymbol{D})$ or $\alpha 2$-chi ${ }^{g t / g t}(\boldsymbol{E}-\boldsymbol{F})$ e12.5 mouse embryos. I, Number of LMC motor neurons expressed as the average number of total (Foxp ${ }^{+}$) LMC neurons per section (\#

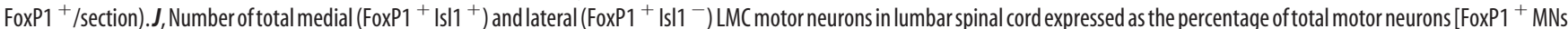
(\%)]. $\boldsymbol{K}-\boldsymbol{R}$, Detection of IsI1 (green) and EphA4 (red) protein, Is/1 and EphB1 mRNA in the spinal cord of mouse e12.5 $\alpha 2$-chi ${ }^{g t /+}(\boldsymbol{K}-\boldsymbol{L})$ or $\alpha 2$-chipt/gt $(\boldsymbol{O}-\boldsymbol{R})$ embryos. The expression and localization of EphA4, EphB1, and Is/1 in LMC are not obviously changed compared with control littermates. Number of embryos quantified: $n=7$ for all experimental groups. Error bars indicate SD; n.s., not

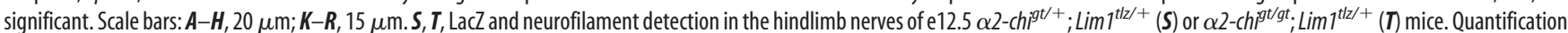
of LacZ signals in both groups expressed as, respectively, percentage in dorsal and ventral limb nerves [lacZ Fluo Int (\%)]. Number of embryos: $n=6(S), 7(T)$. d, Dorsal; $v$, ventral; NF, neurofilament; $\alpha 2$-chi, $\alpha 2$-chimaerin. Error bars indicate SD; ${ }^{* * *} p<0.001 ;{ }^{* *} p<0.01$; statistical significance computed using Student's unpaired $t$ test; all values are mean \pm SD. Scale bars in $\boldsymbol{A}-\boldsymbol{D}, 120 \mu \mathrm{m}$.

appears grossly normal (Beg et al., 2007). The postnatal retrograde labeling experiments revealed that, in $\alpha 2^{g t / g t}$ mutants, adult $\mathrm{BF}$ flexor muscles receive apparently normal innervation from medial LMC neurons, but also aberrant innervation from lateral LMC neurons. The observed cellular defect suggests that antagonistic thigh muscles within the hindlimb might be simultaneously activated during a locomotor task in $\alpha 2^{g t / g t}$ mutants. To explore this possibility, we examined the performance of 10- to 12 -week-old $\alpha 2^{g t / g t}$ mutant and wild-type littermates in a series of locomotor behavioral tasks. First, we determined the overall extent of locomotor activity using an open field test and observed that $\alpha 2^{g t / g t}$ mutants were significantly less active compared with wild-type littermates (Fig. 7A; total horizontal beam breaks; $p<$ 0.001 ). Furthermore, hindlimb rearing was also significantly reduced in $\alpha 2^{g t / g t}$ mutant mice (Fig. $7 B$ vs total vertical beam breaks; $p<0.001$ ), which may reflect a general decrease in hindlimb strength (LeDoux, 2005). Second, in a rota-rod test, which evaluates motor coordination and muscle fatigue (Pritchett and Mulder, 2003), $\alpha 2^{g t / g t}$ mutant mice displayed a significantly shorter latency to fall from a static rota-rod $(20 \mathrm{rpm})$ compared with control animals (Fig. $7 C$; $p<0.05$ ). We next tested $\alpha 2^{g t / g t}$ mutants on an accelerating rota-rod $(4-40 \mathrm{rpm})$ 

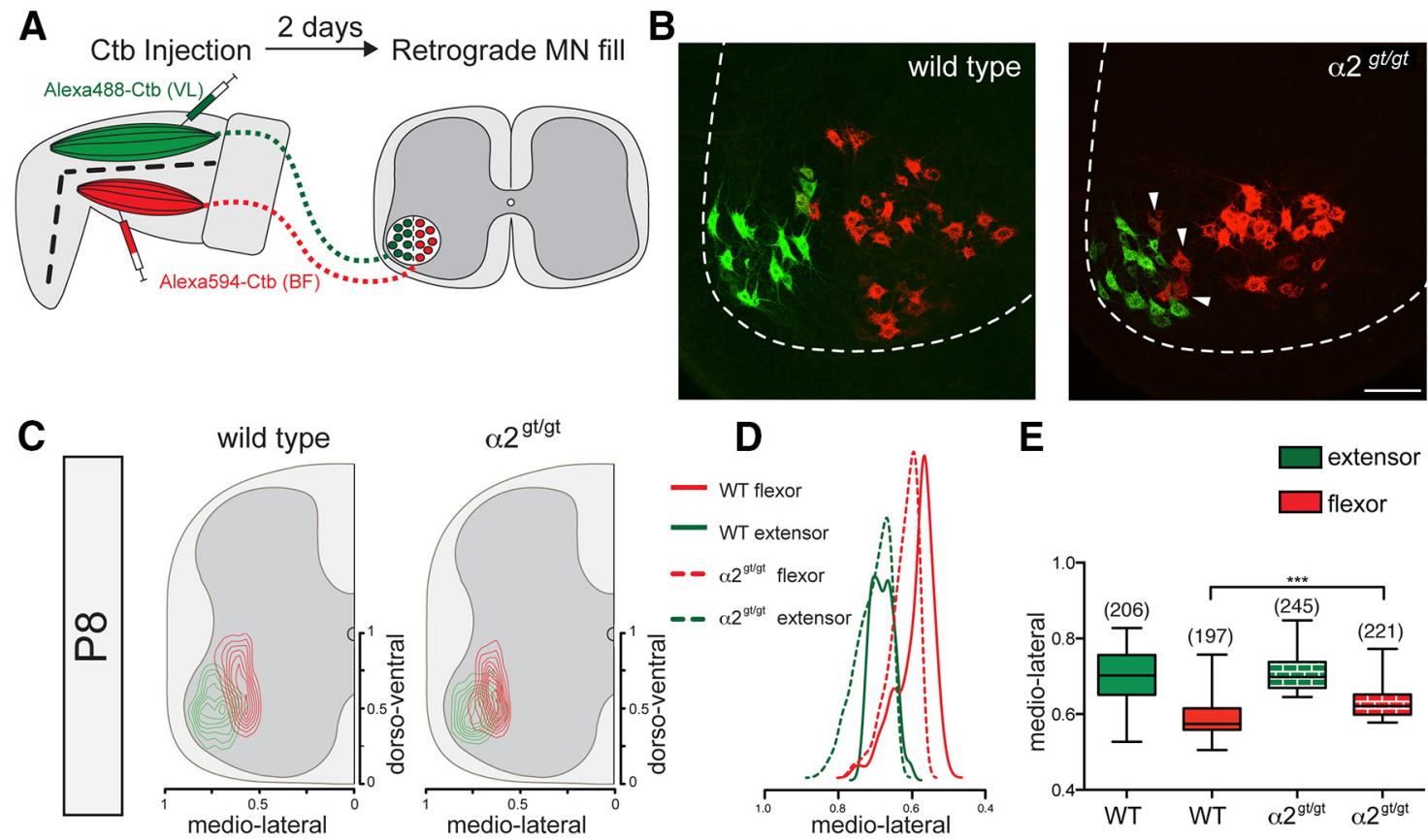

E
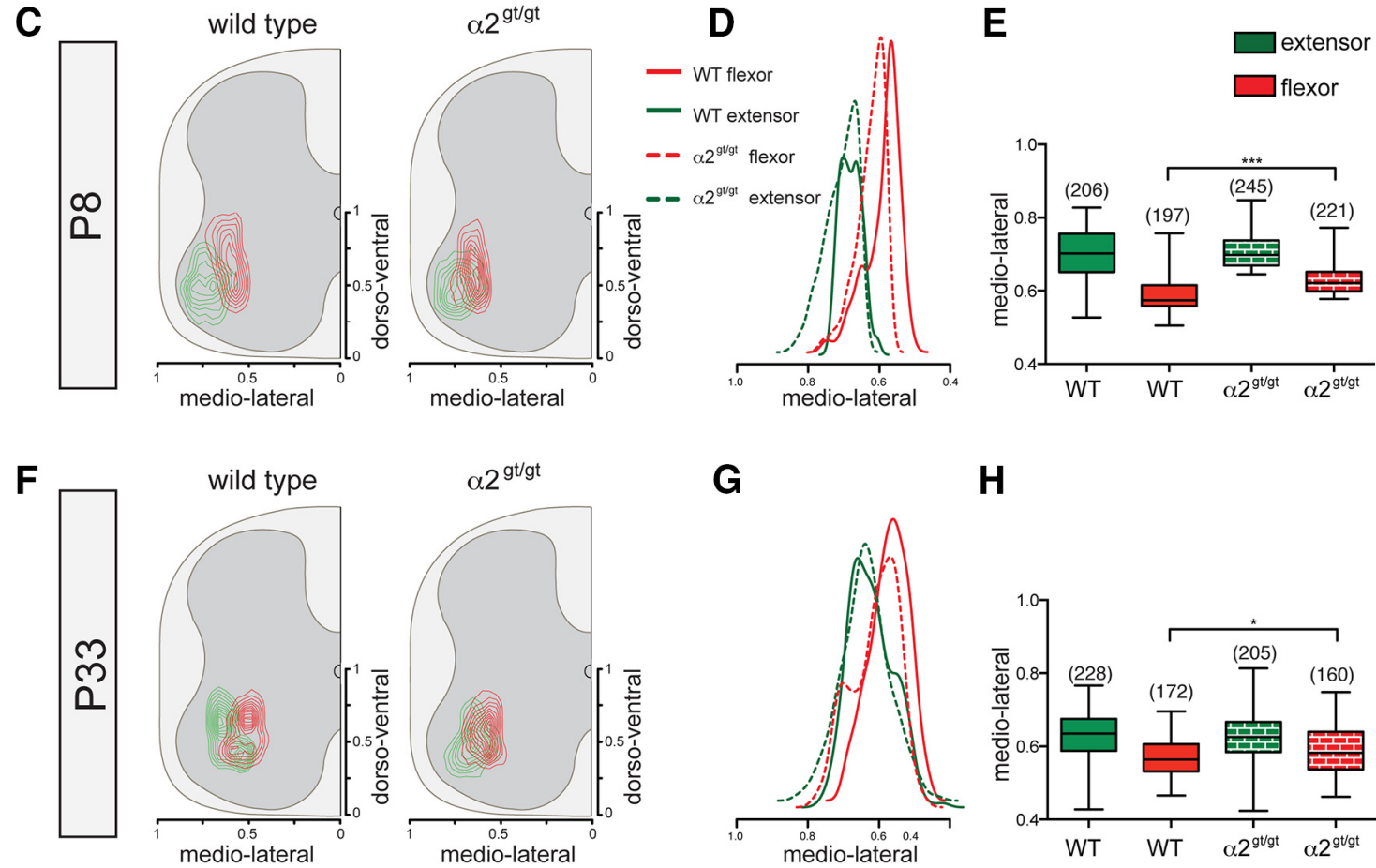

H

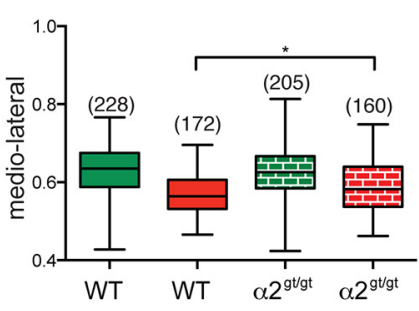

Figure 6. Lateral LMC motor neurons misproject to flexor muscles in postnatal mice. A, Schematic of hindlimb knee extensor (green, vastus lateralis) and flexor (red, bicep femoris) muscles. Muscles are colored according to which fluorescent Alexa Fluor-Ctb injection was injected. B, Representative images of retrogradely labeled LMC motor neurons in P8 spinal cord sections. Scale bar, $100 \mu \mathrm{m} . C, F$, Transverse density contour plots of labeled motor neurons for P8 and P33 wild-type and $\alpha 2^{g t / g t}$ mice. D, G, Kernel density plot for mediolateral LMC position of backfill-labeled motor neurons at P8 and P33, respectively (average of $n=10$ animals/genotype: WT flexor vs $\alpha 2^{g t / g t}$ flexor, ${ }^{* * *} p \leq 0.001$; WT extensor vs $\alpha 2^{g t / g t}$ extensor, $p>0.05$, Mann-Whitney). E, H, Medians of mediolateral positions of LMC motor neuron pools within the spinal cord for P8 and P33 animals, respectively (means \pm SD: (P8:WT flexor, $0.697 \pm 0.06$, WT extensor, $0.590 \pm 0.04, \alpha 2^{g t / g t}$ flexor, $0.707 \pm 0.05, \alpha 2^{g t / g t}$ extensor, $0.631 \pm 0.04 ;$ P P3: WT flexor, $0.628 \pm 0.06$, WT extensor, $0.571 \pm 0.05, \alpha 2^{g t / g t}$ flexor, $0.625 \pm 0.07, \alpha 2^{g t / g t}$ extensor, $0.589 \pm 0.06 ; p \leq 0.0001$, ANOVA, post hoc analysis between all flexor vs extensor pairs $p \leq 0.0001$; WT extensor vs $\alpha 2^{g t / g t}$ extensor $p \geq 0.05$; WT flexor vs $\alpha 2^{g t / g t}$ flexor ${ }^{* * * *} p \leq 0.0001$ (P8), * $p \leq 0.05$ (P33), Tukey HSD). Numbers in parentheses represent the total number of backlabeled cells per condition.

over a $3 \mathrm{~d}$ testing period to determine whether there were improvements in motor performance with training (Pritchett and Mulder, 2003). Compared with controls, $\alpha 2^{g t / g t}$ mutants did not significantly improve in their latency to fall or speed at fall (Fig. $7 D, E ; p<0.05)$. Third, automated gait analysis revealed that $\alpha 2^{g t / g t}$ mutants exhibited several significant locomotor defects (Table 1). $\alpha 2^{g t / g t}$ mutants step with a shorter cycle that is characterized by an increase in hindlimb stance and a decrease in swing duration. In addition, mutant animals had a decreased stride length that was significantly more variable compared with controls (Table 1).

Last, to assess limb muscle strength and coordination, we used an inverted screen test requiring animals to hang and support their body weight by grasping a wire grid for an extended period of time (Carlson et al., 2010). In this assay, $\alpha 2^{\text {gt/gt }}$ mutants grasped the screen for the same amount of time as control littermates (Fig. 7F; $p>0.05$ ). However, we observed that $\alpha 2^{g^{t / g t}} \mathrm{mu}-$ tants exhibited a hindlimb abnormality while hanging inverted: every mutant mouse exhibited an uncoordinated hindlimb "hyperflexion" phenotype characterized by the hindlimb and toes contracting toward the body, in contrast to control animals, which never exhibited this phenotype [Fig. 7G,H; $n=10 / 10$ $\left(\alpha 2^{2^{t / g t}}\right)$ vs 0/10 (wild-type)]. Together, these behavioral data suggest that $\alpha 2$-chimaerin function is required for normal neuromuscular function and that the aberrant lateral LMC axon innervation of limb flexor muscles produces a hindlimb "hyperflexion" consistent with uncoordinated antagonistic muscle contraction.

\section{Discussion}

Our experiments demonstrate that $\alpha 2$-chimaerin, a Rac-GAP linked to DRS, is required for Eph receptor tyrosine kinasemediated motor axon repulsion from ephrin-A, but not from ephrin-B. Reflecting this functional specificity, $\alpha 2$-chimaerin loss of function in mice results in discrete motor axon trajectory defects that persist to adulthood, affecting neuromuscular function. 

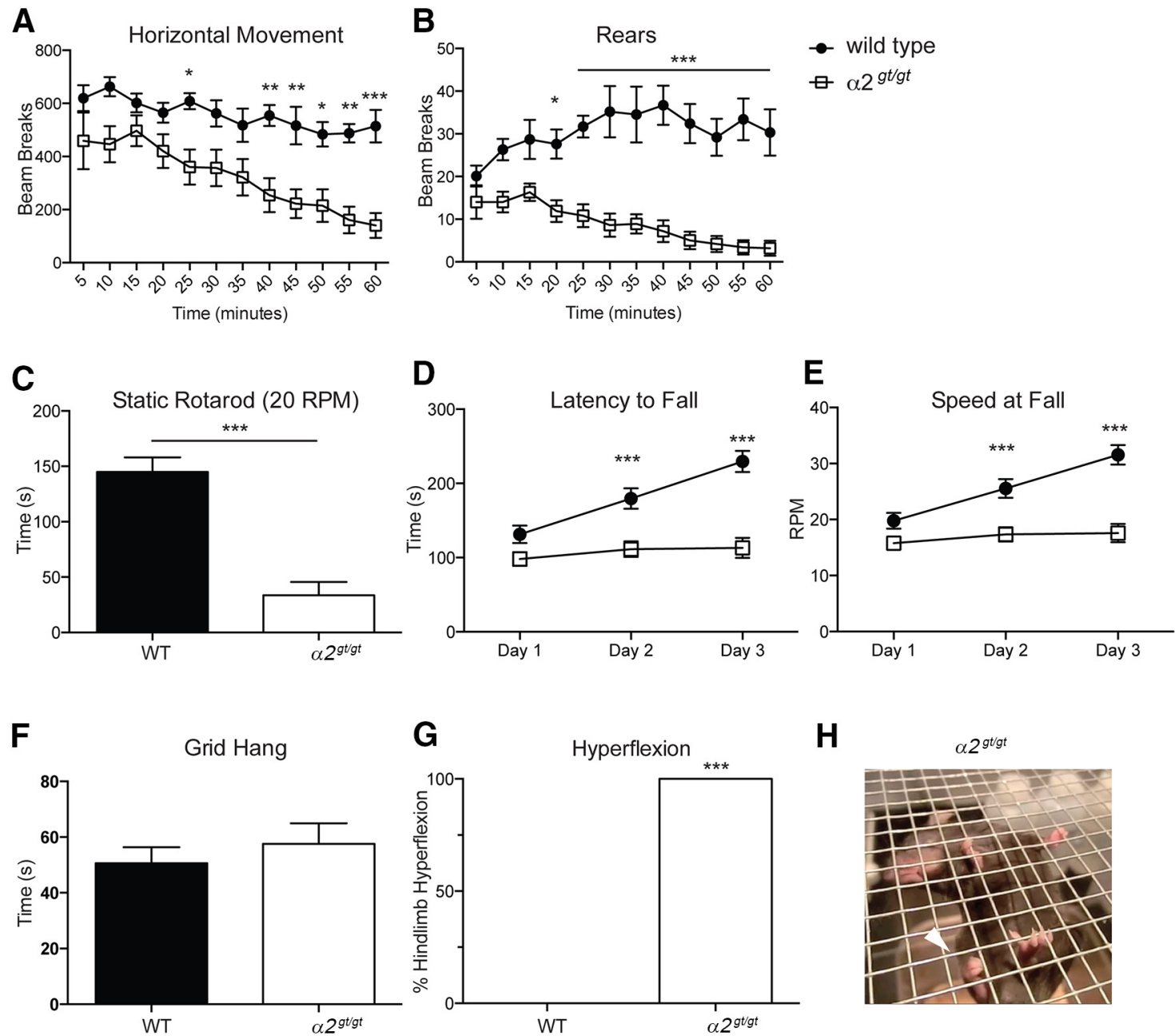

Figure 7. $\alpha 2$-chimaerin mutant mice exhibit locomotor and muscle coordination defects. WT and $\alpha 2^{\text {gt/gt }}$ adult male mice (10-12 weeks, $n=10 /$ genotype) were used for all behavioral experiments. $\boldsymbol{A}-\boldsymbol{B}$, Open field test: total horizontal $(\boldsymbol{A})$ and total vertical $(\boldsymbol{B})$ movement was acquired over the course of $1 \mathrm{~h}$. The number of infrared beam breaks was counted and binned every 5 min. $\alpha 2^{g t / g t}$ mice exhibited significantly decreased locomotion in the open-field compared with control animals (*** $p \leq 0.001$, two-way ANOVA, Bonferroni post hoc, ${ }^{*} p \leq 0.05$, ${ }^{* *} p \leq 0.01,{ }^{* * *} p \leq$ 0.001. C, Static rota-rod: $\alpha 2^{g t / g t}$ mice exhibited a shorter latency to fall from the static rota-rod $(20 \mathrm{rpm})$ compared with controls ${ }^{* * *} p \leq 0.001$, Student's t test). D-E, Accelerating rota-rod: control and $\alpha 2^{g t / g t}$ mice were tested on an accelerating rota-rod $(4-40 \mathrm{rpm}$ ) over $3 \mathrm{~d}$ of training. The time and speed at which mice fell off the apparatus was measured. Wild-type animals exhibited improved motor learning and coordination, whereas $\alpha 2^{g t / g t}$ did not improve over the course of training ( ${ }^{* * *} p \leq 0.001$, two-way ANOVA, Bonferroni posthoc). $\boldsymbol{F}$, Grid-hang: the duration of time the mice hung onto the inverted wire screen was measured. $\alpha 2^{g t / g t}$ mice did not significantly differ from control animals in their ability to hang onto an inverted grid ( $p>0.05$, Student's $t$ test). $\mathbf{G}$, Hyperflexion phenotype: during the grid hang test, animals were scored for exhibiting a hyperflexion phenotype. The percentage of animals/genotype exhibiting hyperflexion of the hindlimbs is presented. Compared with WT controls $(n=0 / 10), \alpha 2^{g t / g t}$ animals $(n=10 / 10)$ exhibited a significant increase in hindlimb hyperflexion $\left({ }^{* * *} p \leq 0.001\right.$, Student's $t$ test). $\boldsymbol{H}$, Representative image of a $\alpha 2^{g t / g t}$ animal exhibiting a hindlimb hyperflexion (white arrowhead). Note the limb and toes pulling and curling toward the body. Errors bars indicate mean \pm SEM.

Table 1. Locomotor analysis for the hindlimbs of WT and $\alpha 2^{g t / g t}$ animals

\begin{tabular}{lccl}
\hline & Wild-type & $\boldsymbol{\alpha 2}^{\text {gt/gt }}$ & $\boldsymbol{p}$-value \\
\hline Gait measurements & & & \\
$\quad$ Stride duration (ms) & $306 \pm 14$ & $273 \pm 24$ & $p<0.0001$ \\
Stride length (cm) & $6.13 \pm 0.209$ & $5.475 \pm 0.301$ & $p<0.0001$ \\
Stride frequency (steps/s) & $3.34 \pm 0.124$ & $3.760 \pm 0.214$ & $p<0.0001$ \\
Stride length variability (cm) & $0.687 \pm 0.254$ & $1.243 \pm 0.416$ & $p<0.002$ \\
$\quad$ Ataxia coefficient & $0.479 \pm 0.260$ & $0.849 \pm 0.312$ & $p<0.01$ \\
Gait phases & & & \\
$\quad$ Percent swing & $38.79 \pm 2.107$ & $29.34 \pm 4.581$ & $p<0.0001$ \\
Percent stance & $61.21 \pm 2.107$ & $70.67 \pm 4.581$ & $p<0.0001$ \\
Percent brake & $17.06 \pm 3.504$ & $19.92 \pm 6.057$ & N.S. \\
Percent propulsion & $44.16 \pm 3.65$ & $50.76 \pm 6.975$ & $p<0.001$ \\
Percent shared & $32.08 \pm 6.823$ & $78.75 \pm 16.24$ & $p<0.0001$ \\
\hline
\end{tabular}

Gait parameters are indicated along with the corresponding $p$-value (Student's $t$ test). Data are shown as mean \pm SEM. N.S., Not significant.
We discuss these findings in terms of the intracellular logic of Rho-GTPase function in axon guidance and the relevance of accurate embryonic axon trajectory selection for adult nervous system function.

\section{$\alpha 2$-chimaerin is a nonredundant and selective regulator of EphA receptor function in motor neurons}

Understanding the logic of Rho-GTPase regulation in axonal pathfinding has proved problematic because Rho-GTPase modulation proteins: (1) exhibit genetic redundancy, (2) act in numerous signaling pathways, and (3) may only partially contribute to a signaling decision (O'Donnell et al., 2009). $\alpha 2$-chimaerin is essentially expressed in all LMC motor neurons, yet our experiments identify at least one subset of LMC neurons and a specific axon trajectory choice where its function is nonredundant. Lateral LMC axons that innervate dorsal limb muscles via, principally, repulsion from ephrin-As through EphA receptors, require 
$\alpha 2$-chimaerin. However, this protein is not required for the mirror ephrin-B:EphB-mediated repulsion of medial LMC axons into the ventral limb. These data strongly imply that lateral LMC neurons do not express a redundant Rac-GAP protein that can compensate for the loss of $\alpha 2$-chimaerin.

In addition to the ephrin-A:EphA signaling system, lateral LMC axons also rely on other signaling events that contribute to the fidelity of LMC axon guidance. These include reverse signaling from EphA4 to ephrin-A5 in LMC axons, attraction to limbexpressed GDNF via c-Ret, and repulsion from Semaphorin 3A (Huber et al., 2005; Kramer et al., 2006; Dudanova et al., 2010; Bonanomi et al., 2012; Dudanova et al., 2012). Might $\alpha 2$ chimaerin function in these processes contribute to the in vivo guidance phenotypes observed in $\alpha 2^{g t / g t}$ mutants? No biochemical evidence of ephrin-A or c-Ret/GFR $\alpha 1$ association with $\alpha 2$ chimaerin exists and, whereas $\alpha 2$-chimaerin is required for EphA4 forward signaling in corticospinal and spinal interneuron axon guidance (Beg et al., 2007; Iwasato et al., 2007; Wegmeyer et al., 2007), it is not required for anterior commissure formation, a process that relies on reverse ephrin-A signaling (Henkemeyer et al., 1996; Dottori et al., 1998; Cowan et al., 2004; Ho et al., 2009). $\alpha 2$-chimaerin has been shown to interact with Plexin-A and Neuropilin receptors and is an essential protein in Sema3Adependent dorsal root ganglion growth cone guidance (Brown et al., 2004; Riccomagno et al., 2012). However, Neuropilin-1 and Sema3A loss of function results in limb nerve defasciculation (Sanyas et al., 2012), whereas Neuropilin-2 knock-out leads to medial LMC pathfinding errors, which we have not observed in $\alpha 2$-chimaerin loss of function (Huber et al., 2005). Nevertheless, to formally exclude all these possibilities, in vitro responses to individual cues such as GDNF, EphA4, or semaphorins should be measured in motor neuron growth cones lacking $\alpha 2$-chimaerin. Therefore, $\alpha 2$-chimaerin is a nonredundant, EphA-specific effector of lateral LMC axon guidance, suggesting that part of the molecular logic of Rho-GTPase deployment might be the restriction of its coupling to a particular family of axon guidance receptors.

\section{Embryonic misprojections persist in $\alpha 2$-chimaerin mutants} $\alpha 2$-chimaerin mutation disrupts specific aspects of embryonic neuromuscular connectivity and our initial hypothesis was that regressive processes might correct these defects during postnatal development. Axon pruning or degradation, as well as apoptosis of improperly wired neurons, have been proposed to correct embryonic axon guidance errors (Cowan et al., 1984). In particular, spinal motor neuron dependence on target muscle derived neurotrophins would be one attractive mechanism for deleting inappropriately connected motor neurons (Buss et al., 2006). Our retrograde tracing experiments in juvenile and adult animals revealed the persistence of aberrant lateral LMC axonal misprojections, reflecting the embryonic defects without any overt consequence on motor neuron survival. One formal possibility is that $\alpha 2$-chimaerin itself is required for the elimination of aberrantly connected LMC neurons: recently, the paralog $\beta 2$-chimaerin was shown to be required for stereotyped Sema3F-dependent pruning of the hippocampal infrapyramidal tract (IPT), which also relies on ephrin-B reverse signaling (Xu and Henkemeyer, 2009; Riccomagno et al., 2012). In vivo analysis demonstrates that $\alpha 2$ chimaerin is not required for hippocampal IPT pruning (A.A. Beg, unpublished data), suggesting, at least in the context of stereotyped CNS developmental pruning, that $\alpha 2$-chimaerin is not absolutely required for semaphoring and ephrin-dependent regressive signaling.
EphA4 and c-Ret mutations also cause the redirection of lateral LMC axons into the ventral limb nerve and abnormal innervation of flexor muscles (Helmbacher et al., 2000; Kramer et al., 2006; Bonanomi et al., 2012). However, it is unclear whether these defects persist to adulthood because of non-axon guidance functions of EphA4 and c-Ret and the lack of retrograde labeling data. Consistent with our genetic experiments, cellular manipulations in the chicken argue that motor neurons innervating inappropriate muscles are not preferentially eliminated (Landmesser and O'Donovan, 1984). Therefore, the idea that apoptotic elimination of motor neurons is a highly specific process needs refinement (Gould and Oppenheim, 2004).

\section{Neuromuscular function impairments in $\alpha 2$-chimaerin mutants}

Skilled movement depends on the precise spatial, temporal, and sequential activation of functionally opposed muscles. To ensure coordinated locomotion, antagonistic flexor and extensor muscles within a limb must be activated at opposing intervals during the walking cycle. Manipulation of LMC neuron flexor-extensor connectivity by surgical muscle transposition or nerve cross union results in severe locomotor defects that are not corrected through spinal locomotor circuit plasticity (Sperry, 1945; Gordon et al., 1986). Similarly, locomotor and postural abnormalities consistent with flexion-extension defects have been described in EphA4 and c-Ret adult mutant mice, but adult neuromuscular connectivity has not been investigated in these mutants (Helmbacher et al., 2000; Akay et al., 2006; Kramer et al., 2006). $\alpha 2$-chimaerin mutant mice exhibit a hopping gait phenotype attributed to defects in corticospinal and spinal central pattern generator connectivity. Electrophysiological recordings from isolated spinal cords of $\alpha 2$-chimaerin constituitive knock-out mice demonstrate that ipsilateral flexor and extensor motor neuron firing correctly occurs at opposing phases of the locomotor cycle, suggesting the upstream interneuronal circuits that drive the activation and timing of lateral and medial LMC motor neurons are normal. (Kullander et al., 2003; Egea et al., 2005; Iwasato et al., 2007; Wegmeyer et al., 2007). Moreover, it has been demonstrated recently that selective ablation of $\alpha 2$-chimaerin in Vglut ${ }^{+}$spinal interneurons is sufficient to cause synchronous hopping (Borgius et al., 2014). These data, combined with anatomical tracings revealing the persistence of embryonic flexorextensor neuromuscular connectivity defects in adult $\alpha 2^{g t / g t}$ mutants, allowed us to speculate on the neuromuscular consequence of abnormal innervation of flexor muscles by lateral LMC neurons. Our tracing experiments argue that, in $\alpha 2^{g t / g t}$ mutants, medial LMC motor neurons appropriately innervate flexor muscles. In contrast, although the majority of lateral LMC motor neurons correctly innervate extensor muscles, a subset incorrectly innervates flexor muscles. Therefore, one prediction of such altered neuromuscular connectivity might be the activation of flexors at all phases of the flexor-extensor cycle. However, we cannot formally exclude other, more complex interpretations such as prolonged or intermittent flexor muscle activation within the extensor phase that might account for the 'hyperflexion" phenotype.

Why is the $\alpha 2^{\text {gt/gt }}$ mutant hindlimb "hyperflexion" only observed in certain behavioral contexts, such as during the upsidedown hanging grid test? One possible explanation is that the neuromuscular connectivity between lateral LMC neurons and flexor muscles is weaker than that between appropriately matched medial LMC neurons and their targets. Such weakly connected LMC neurons are not recruited in normal locomotor 
behaviors (Granit et al., 1957), but a motor task that recruits larger populations of motor neurons could result in their activation, leading to hyperflexion. Selective stimulation of miswired lateral LMC neurons coupled with flexor muscle electromyography would provide critical insight to these models; however, the genetic tools for such experiments are not presently available. Although our understanding of the observed locomotor phenotypes is still rudimentary, the $\alpha 2$-chimaerin mutant represents a promising genetic model for the dissection of flexor-extensor motor function and related neuromuscular pathophysiology.

Our observations add spinal motor neurons to the register of skilled movement circuits whose function of which depends on $\alpha 2$-chimaerin. Defects in connectivity of corticospinal projection neurons, central pattern generator spinal interneurons (Beg et al., 2007; Iwasato et al., 2007; Wegmeyer et al., 2007), and oculomotor nerve motor neurons (Miyake et al., 2008) have all been linked to human and mouse $\alpha 2$-chimaerin mutations.

A pathological hallmark of DRS is the misinnervation of abductor and adductor muscles, which is proposed to cause cocontraction and globe retraction of the eye (Miyake et al., 2008), a neuromuscular phenotype that is strikingly analogous to the limb flexor-extensor coactivation defect that we observe in $\alpha 2^{g t / g t} \mathrm{mu}-$ tants. Although defects in Sema3, HGF, and CXL12 signaling can cause DRS-like oculomotor axon guidance defects in animal models (Ferrario et al., 2012), the axon guidance receptors for which loss of function contributes to DRS are unknown. Intriguingly, chick oculomotor axons are repelled by ephrin-A5 (Ferrario et al., 2012), suggesting that defects in $\alpha 2$-chimaerin-mediated ephrinA:EphA signaling may play a role in DRS pathogenesis. Furthermore, neuromusculoskeletal abnormalities, such as club foot, occur with high incidence in DRS patients (Marshman et al., 2000), potentially implicating defects in $\alpha 2$-chimaerin and/or EphA signaling in such comorbidities.

\section{References}

Akay T, Acharya HJ, Fouad K, Pearson KG (2006) Behavioral and electromyographic characterization of mice lacking EphA4 receptors. J Neurophysiol 96:642-651. CrossRef Medline

Bashaw GJ, Klein R (2010) Signaling from axon guidance receptors. Cold Spring Harb Perspect Biol 2:a001941. Medline

Beg AA, Sommer JE, Martin JH, Scheiffele P (2007) alpha2-Chimaerin is an essential EphA4 effector in the assembly of neuronal locomotor circuits. Neuron 55:768-778. CrossRef Medline

Bonanomi D, Chivatakarn O, Bai G, Abdesselem H, Lettieri K, Marquardt T, Pierchala BA, Pfaff SL (2012) Ret is a multifunctional coreceptor that integrates diffusible- and contact-axon guidance signals. Cell 568-582.

Borgius L, Nishimaru H, Caldeira V, Kunugise Y, Löw P, Reig R, Itohara S, Iwasato T, Kiehn O (2014) Spinal glutamatergic neurons defined by epha4 signaling are essential components of normal locomotor circuits. J Neurosci 34:3841-3853. CrossRef Medline

Brown M, Jacobs T, Eickholt B, Ferrari G, Teo M, Monfries C, Qi RZ, Leung T, Lim L, Hall C (2004) Alpha2-chimaerin, cyclin-dependent Kinase 5/p35, and its target collapsin response mediator protein-2 are essential components in semaphorin 3A-induced growth-cone collapse. J Neurosci 24:8994-9004. CrossRef Medline

Buss RR, Sun W, Oppenheim RW (2006) Adaptive roles of programmed cell death during nervous system development. Annu Rev Neurosci 29:1-35. CrossRef Medline

Carlson CG, Rutter J, Bledsoe C, Singh R, Hoff H, Bruemmer K, Sesti J, Gatti F, Berge J, McCarthy L (2010) A simple protocol for assessing inter-trial and inter-examiner reliability for two noninvasive measures of limb muscle strength. J Neurosci Methods 186:226-230. CrossRef Medline

Clark C, Austen O, Poparic I, Guthrie S (2013) alpha2-Chimaerin regulates a key axon guidance transition during development of the oculomotor projection. J Neurosci 33:16540-16551. CrossRef Medline

Cowan CA, Yokoyama N, Saxena A, Chumley MJ, Silvany RE, Baker LA, Srivastava D, Henkemeyer M (2004) Ephrin-B2 reverse signaling is re- quired for axon pathfinding and cardiac valve formation but not early vascular development. Dev Biol 271:263-271. CrossRef Medline

Cowan CW, Shao YR, Sahin M, Shamah SM, Lin MZ, Greer PL, Gao S, Griffith EC, Brugge JS, Greenberg ME (2005) Vav family GEFs link activated Ephs to endocytosis and axon guidance. Neuron 46:205-217. CrossRef Medline

Cowan WM, Fawcett JW, O'Leary DD, Stanfield BB (1984) Regressive events in neurogenesis. Science 225:1258-1265. CrossRef Medline

Crone SA, Zhong G, Harris-Warrick R, Sharma K (2009) In mice lacking V2a interneurons, gait depends on speed of locomotion. J Neurosci 29: 7098-7109. CrossRef Medline

Dasen JS, De Camilli A, Wang B, Tucker PW, Jessell TM (2008) Hox repertoires for motor neuron diversity and connectivity gated by a single accessory factor, FoxP1. Cell 134:304-316. CrossRef Medline

Dodd J, Jessell TM (1988) Axon guidance and the patterning of neuronal projections in vertebrates. Science 242:692-699. CrossRef Medline

Dottori M, Hartley L, Galea M, Paxinos G, Polizzotto M, Kilpatrick T, Bartlett PF, Murphy M, Köntgen F, Boyd AW (1998) EphA4 (Sek1) receptor tyrosine kinase is required for the development of the corticospinal tract. Proc Natl Acad Sci U S A 95:13248-13253. CrossRef Medline

Dudanova I, Gatto G, Klein R (2010) GDNF acts as a chemoattractant to support ephrinA-induced repulsion of limb motor axons. Curr Biol $2150-2156$

Dudanova I, Kao TJ, Herrmann JE, Zheng B, Kania A, Klein R (2012) Genetic evidence for a contribution of EphA:ephrinA reverse signaling to motor axon guidance. J Neurosci 32:5209-5215. CrossRef Medline

Eberhart J, Swartz ME, Koblar SA, Pasquale EB, Krull CE (2002) EphA4 constitutes a population-specific guidance cue for motor neurons. Dev Biol 89-101.

Egea J, Nissen UV, Dufour A, Sahin M, Greer P, Kullander K, Mrsic-Flogel TD, Greenberg ME, Kiehn O, Vanderhaeghen P, Klein R (2005) Regulation of EphA 4 kinase activity is required for a subset of axon guidance decisions suggesting a key role for receptor clustering in Eph function. Neuron 47:515-528. CrossRef Medline

Ferrario JE, Baskaran P, Clark C, Hendry A, Lerner O, Hintze M, Allen J, Chilton JK, Guthrie S (2012) Axon guidance in the developing ocular motor system and Duane retraction syndrome depends on Semaphorin signaling via alpha2-chimaerin. Proc Natl Acad Sci U S A 109:1466914674. CrossRef Medline

Gordon T, Stein RB, Thomas CK (1986) Innervation and function of hindlimb muscles in the cat after cross-union of the tibial and peroneal nerves. J Physiol 374:429-441. CrossRef Medline

Gould TW, Oppenheim RW (2004) The function of neurotrophic factor receptors expressed by the developing adductor motor pool in vivo. J Neurosci 24:4668-4682. CrossRef Medline

Govek EE, Newey SE, Van Aelst L (2005) The role of the Rho GTPases in neuronal development. Genes Dev 19:1-49. CrossRef Medline

Granit R, Phillips CG, Skoglund S, Steg G (1957) Differentiation of tonic from phasic alpha ventral horn cells by stretch, pinna and crossed extensor reflexes. J Neurophysiol 20:470-481. Medline

Hall C, Michael GJ, Cann N, Ferrari G, Teo M, Jacobs T, Monfries C, Lim L (2001) alpha2-chimaerin, a Cdc42/Racl regulator, is selectively expressed in the rat embryonic nervous system and is involved in neuritogenesis in N1E-115 neuroblastoma cells. J Neurosci 5191-5202.

Hamburger V, Hamilton HL (1992) A series of normal stages in the development of the chick embryo. 1951. Dev Dyn 195:231-272. CrossRef Medline

Helmbacher F, Schneider-Maunoury S, Topilko P, Tiret L, Charnay P (2000) Targeting of the EphA4 tyrosine kinase receptor affects dorsal/ventral pathfinding of limb motor axons. Development 127:3313-3324. Medline

Henkemeyer M, Orioli D, Henderson JT, Saxton TM, Roder J, Pawson T, Klein R (1996) Nuk controls pathfinding of commissural axons in the mammalian central nervous system. Cell 86:35-46. CrossRef Medline

Ho SK, Kovacević N, Henkelman RM, Boyd A, Pawson T, Henderson JT (2009) EphB2 and EphA4 receptors regulate formation of the principal inter-hemispheric tracts of the mammalian forebrain. Neuroscience 160: 784-795. CrossRef Medline

Huber AB, Kania A, Tran TS, Gu C, De Marco Garcia N, Lieberam I, Johnson D, Jessell TM, Ginty DD, Kolodkin AL (2005) Distinct roles for secreted semaphorin signaling in spinal motor axon guidance. Neuron 949-964.

Iwasato T, Katoh H, Nishimaru H, Ishikawa Y, Inoue H, Saito YM, Ando R, Iwama M, Takahashi R, Negishi M, Itohara S (2007) Rac-GAP alpha- 
chimerin regulates motor-circuit formation as a key mediator of EphrinB3/EphA4 forward signaling. Cell 742-753.

Jones CL (1979) The morphogenesis of the thigh of the mouse with special reference to tetrapod muscle homologies. J Morphol 162:275-309. CrossRef Medline

Kania A, Jessell TM (2003) Topographic motor projections in the limb imposed by LIM homeodomain protein regulation of ephrin-a:epha interactions. Neuron 38:581-596. CrossRef Medline

Kania A, Johnson RL, Jessell TM (2000) Coordinate roles for LIM homeobox genes in directing the dorsoventral trajectory of motor axons in the vertebrate limb. Cell 161-173.

Kao T-J, Kania A (2011) Ephrin-mediated cis-attenuation of Eph receptor signaling is essential for spinal motor axon guidance. Neuron 76-91.

Kao T-J, Palmesino E, Kania A (2009) SRC family kinases are required for limb trajectory selection by spinal motor axons. J Neurosci 5690-5700.

Kao TJ, Law C, Kania A (2012) Eph and ephrin signaling: lessons learned from spinal motor neurons. Semin Cell Dev Biol 23:83-91. CrossRef Medline

Klein R (2012) Eph/ephrin signalling during development. Development 139:4105-4109. CrossRef Medline

Kolodkin AL, Tessier-Lavigne M (2011) Mechanisms and molecules of neuronal wiring: a primer. Cold Spring Harb Perspect Biol 3:pii:a001727. CrossRef Medline

Kramer ER, Knott L, Su F, Dessaud E, Krull CE, Helmbacher F, Klein R (2006) Cooperation between GDNF/Ret and ephrinA/EphA4 signals for motor-axon pathway selection in the limb. Neuron 35-47.

Kullander K, Butt SJB, Lebret JM, Lundfald L, Restrepo CE, Rydström A, Klein R, Kiehn O (2003) Role of EphA4 and EphrinB3 in local neuronal circuits that control walking. Science 1889-1892.

Lance-Jones C, Landmesser L (1981) Pathway selection by chick lumbosacral motoneurons during normal development. Proc R Soc Lond B Biol Sci 1-18.

Landmesser L (1978) The development of motor projection patterns in the chick hind limb. J Physiol 391-414.

Landmesser LT, O'Donovan MJ (1984) The activation patterns of embryonic chick motoneurones projecting to inappropriate muscles. J Physiol 347:205-224. CrossRef Medline

LeDoux M (2005) Animal models of movement disorders.

Luo L (2002) Actin cytoskeleton regulation in neuronal morphogenesis and structural plasticity. Annu Rev Cell Dev Biol 18:601-635. CrossRef Medline

Luria V, Laufer E (2007) Lateral motor column axons execute a ternary trajectory choice between limb and body tissues. Neural Dev 2:13. CrossRef Medline

Luria V, Krawchuk D, Jessell TM, Laufer E, Kania A (2008) Specification of motor axon trajectory by ephrin-B:EphB signaling: symmetrical control of axonal patterning in the developing limb. Neuron 1039-1053.

Marshman WE, Schalit G, Jones RB, Lee JP, Matthews TD, McCabe S (2000) Congenital anomalies in patients with Duane retraction syndrome and their relatives. J Aapos 4:106-109. CrossRef Medline

McHanwell S, Biscoe TJ (1981) The localization of motoneurons supplying the hindlimb muscles of the mouse. Philosophical transactions of the Royal Society of London Series B, Biological sciences 293:477-508. CrossRef Medline

Miyake N, Chilton J, Psatha M, Cheng L, Andrews C, Chan WM, Law K, Crosier M, Lindsay S, Cheung M, Allen J, Gutowski NJ, Ellard S, Young E, Iannaccone A, Appukuttan B, Stout JT, Christiansen S, Ciccarelli ML, Baldi A, et al. (2008) Human CHN1 mutations hyperactivate alpha2chimaerin and cause Duane's retraction syndrome. Science 321:839-843. CrossRef Medline

Momose T, Tonegawa A, Takeuchi J, Ogawa H, Umesono K, Yasuda K (1999) Efficient targeting of gene expression in chick embryos by microelectroporation. Dev Growth Differ 41:335-344. CrossRef Medline

Ng J, Nardine T, Harms M, Tzu J, Goldstein A, Sun Y, Dietzl G, Dickson BJ,
Luo L (2002) Rac GTPases control axon growth, guidance and branching. Nature $442-447$.

O’Donnell M, Chance R, Bashaw G (2009) Axon growth and guidance: receptor regulation and signal transduction. Annu Rev Neurosci

Palmesino E, Rousso DL, Kao TJ, Klar A, Laufer E, Uemura O, Okamoto H, Novitch BG, Kania A (2010) Foxp1 and lhx1 coordinate motor neuron migration with axon trajectory choice by gating Reelin signalling. PLoS Biol 8:e1000446. Medline

Pritchett K, Mulder GB (2003) The rotarod. Contemp Top Lab Anim Sci 42:49. Medline

Riccomagno MM, Hurtado A, Wang H, Macopson JG, Griner EM, Betz A, Brose N, Kazanietz MG, Kolodkin AL (2012) The RacGAP beta2Chimaerin selectively mediates axonal pruning in the hippocampus. Cell 149:1594-1606. CrossRef Medline

Rozen S, Skaletsky H (2000a) Primer3 on the WWW for general users and for biologist programmers. Methods Mol Biol 132:365-386. Medline

Sanyas I, Bozon M, Moret F, Castellani V (2012) Motoneuronal Sema3C is essential for setting stereotyped motor tract positioning in limb-derived chemotropic semaphorins. Development 139:3633-3643. CrossRef Medline

Schaeren-Wiemers N, Gerfin-Moser A (1993) A single protocol to detect transcripts of various types and expression levels in neural tissue and cultured cells: in situ hybridization using digoxigenin-labelled cRNA probes. Histochem Cell Biol 100:431-440. Medline

Seiradake E, Schaupp A, del Toro Ruiz D, Kaufmann R, Mitakidis N, Harlos K, Aricescu AR, Klein R, Jones EY (2013) Structurally encoded intraclass differences in EphA clusters drive distinct cell responses. Nat Struct Mol Biol 20:958-964. CrossRef Medline

Shamah SM, Lin MZ, Goldberg JL, Estrach S, Sahin M, Hu L, Bazalakova M, Neve RL, Corfas G, Debant A, Greenberg ME (2001) EphA receptors regulate growth cone dynamics through the novel guanine nucleotide exchange factor ephexin. Cell 105:233-244. CrossRef Medline

Shi L, Fu WY, Hung KW, Porchetta C, Hall C, Fu AK, Ip NY (2007) Alpha2chimaerin interacts with EphA4 and regulates EphA4-dependent growth cone collapse. Proc Natl Acad Sci U S A 104:16347-16352. CrossRef Medline

Sperry RW (1945) The problem of central nervous reorganization after nerve regeneration and muscle transposition. Q Rev Biol 20:311-369. CrossRef Medline

Tessier-Lavigne M, Goodman CS (1996) The molecular biology of axon guidance. Science 1123-1133.

Tosney KW, Landmesser LT (1985) Specificity of early motoneuron growth cone outgrowth in the chick embryo. J Neurosci 2336-2344.

Tripodi M, Stepien AE, Arber S (2011) Motor antagonism exposed by spatial segregation and timing of neurogenesis. Nature 479:61-66. CrossRef Medline

Tsuchida T, Ensini M, Morton SB, Baldassare M, Edlund T, Jessell TM, Pfaff SL (1994a) Topographic organization of embryonic motor neurons defined by expression of LIM homeobox genes. Cell 79:957-970. CrossRef Medline

Tsuchida T, Ensini M, Morton SB, Baldassare M, Edlund T, Jessell TM, Pfaff SL (1994b) Topographic organization of embryonic motor neurons defined by expression of LIM homeobox genes. Cell 957-970.

Wegmeyer H, Egea J, Rabe N, Gezelius H, Filosa A, Enjin A, Varoqueaux F, Deininger K, Schnütgen F, Brose N, Klein R, Kullander K, Betz A (2007) EphA4-dependent axon guidance is mediated by the RacGAP alpha2chimaerin. Neuron 55:756-767. CrossRef Medline

Wong K, Ren XR, Huang YZ, Xie Y, Liu G, Saito H, Tang H, Wen L, BradyKalnay SM, Mei L, Wu JY, Xiong WC, Rao Y (2001) Signal transduction in neuronal migration: roles of GTPase activating proteins and the small GTPase Cdc42 in the Slit-Robo pathway. Cell 107:209-221. CrossRef Medline

Xu NJ, Henkemeyer M (2009) Ephrin-B3 reverse signaling through Grb4 and cytoskeletal regulators mediates axon pruning. Nat Neurosci 12:268 276. CrossRef Medline 